\title{
Characteristics of Model Tropical Cyclone Climatology and the Large-Scale Environment ${ }^{\mathscr{D}}$
}

\author{
Suzana J. Camargo, ${ }^{\mathrm{a}}$ Claudia F. Giulivi, ${ }^{\mathrm{a}}$ AdAm H. Sobel,${ }^{\mathrm{b}}$ Allison A. Wing, ${ }^{\mathrm{c}}$ Daehyun Kim, ${ }^{\mathrm{d}}$ \\ Yumin Moon, ${ }^{\mathrm{d}}$ JefFrey D. O. Strong, ${ }^{\mathrm{a}}$ Anthony D. Del Genio, ${ }^{\mathrm{e}}$ MaXwell Kelley, ${ }^{\mathrm{e}}$ \\ Hiroyuki Murakami, ${ }^{\mathrm{f}}$ KeVIn A. ReED, ${ }^{\mathrm{g}}$ EnRICO SCOCCIMARro, ${ }^{\mathrm{h}}$ Gabriel A. VeCChi, ${ }^{\mathrm{i}}$ \\ Michael F. WeHNER, ${ }^{\mathrm{j}}$ COLIN ZARZYCKI ${ }^{\mathrm{k}}$ AND Ming ZHAO ${ }^{\mathrm{f}}$ \\ ${ }^{a}$ Lamont-Doherty Earth Observatory, Columbia University, Palisades, New York \\ ${ }^{\mathrm{b}}$ Department of Applied Physics and Applied Mathematics, Department of Earth and Environmental Sciences, \\ Columbia University, New York, New York \\ ${ }^{\mathrm{c}}$ Department of Earth, Ocean and Atmospheric Science, Florida State University, Talahassee, Florida \\ ${ }^{\mathrm{d}}$ Department of Atmospheric Sciences, University of Washington, Seattle, Washington \\ ${ }^{\mathrm{e}}$ NASA Goddard Institute for Space Studies, New York, New York \\ ${ }^{\mathrm{f}}$ NOAA/Geophysical Fluid Dynamics Laboratory, Princeton, New Jersey \\ ${ }^{\mathrm{g}}$ School of Marine and Atmospheric Sciences, Stony Brook University, Stony Brook, New York \\ ${ }^{\mathrm{h}}$ Fondazione Centro Euro-Mediterraneo sui Cambiamenti Climatici, Bologna, Italy \\ ${ }^{i}$ Princeton University, Princeton, New Jersey \\ ${ }^{\mathrm{j}}$ Lawrence Berkeley National Laboratory, Berkeley, California \\ ${ }^{\mathrm{k}}$ The Pennsylvania State University, University Park, Pennsylvania
}

(Manuscript received 5 July 2019, in final form 18 February 2020)

\begin{abstract}
Here we explore the relationship between the global climatological characteristics of tropical cyclones (TCs) in climate models and the modeled large-scale environment across a large number of models. We consider the climatology of TCs in 30 climate models with a wide range of horizontal resolutions. We examine if there is a systematic relationship between the climatological diagnostics for the TC activity [number of tropical cyclones (NTC) and accumulated cyclone energy (ACE)] by hemisphere in the models and the environmental fields usually associated with TC activity, when examined across a large number of models. For low-resolution models, there is no association between a conducive environment and TC activity, when integrated over space (tropical hemisphere) and time (all years of the simulation). As the model resolution increases, for a couple of variables, in particular vertical wind shear, there is a statistically significant relationship in between the models' TC characteristics and the environmental characteristics, but in most cases the relationship is either nonexistent or the opposite of what is expected based on observations. It is important to stress that these results do not imply that there is no relationship between individual models' environmental fields and their TC activity by basin with respect to intraseasonal or interannual variability or due to climate change. However, it is clear that when examined across many models, the models' mean state does not have a consistent relationship with the models' mean TC activity. Therefore, other processes associated with the model physics, dynamical core, and resolution determine the climatological TC activity in climate models.
\end{abstract}

\section{Introduction}

Since the 1970s climate models have been known to simulate tropical cyclone-like structures (Manabe et al. 1970; Bengtsson et al. 1982; Haarsma et al. 1993). These

Supplemental information related to this paper is available at the Journals Online website: https://doi.org/10.1175/JCLI-D-190500.s1.

Corresponding author: Suzana J. Camargo, suzana@ldeo.columbia.edu models have been used for projections of tropical cyclone (TC) activity under anthropogenic climate change (Broccoli and Manabe 1990; Bengtsson et al. 1996) and their use for such projections continues to this day, using low- (Camargo 2013; Tory et al. 2013; Chand et al. 2017) and high-horizontal-resolution models (Murakami et al. 2012b; Knutson et al. 2013; Manganello et al. 2014; Bhatia et al. 2018; Bacmeister et al. 2018). Another common use of climate models is for TC dynamical forecasts on seasonal (Vitart et al. 2001; Camargo and Barnston 2009; Manganello et al. 2016; Camp et al. 2019; 
G. Zhang et al. 2019; W. Zhang et al. 2019) and subseasonal time scales (Lee et al. 2018; Camp et al. 2018; Gregory et al. 2019; Zhao et al. 2019). A recent review on this topic is provided by Camargo and Wing (2016).

Both TC future projections, as well as the subseasonal and seasonal forecasts, are dependent on the ability of the models to simulate TC climatological characteristics. Various types of bias correction procedures can be applied to the model ouput (Camargo and Zebiak 2002; Camargo and Barnston 2009; Camp et al. 2018). However, these regional bias corrections cannot be used to obtain an unbiased global TC climatology and could lead to errors in TC projections and forecasts (Murakami et al. 2014; Lee et al. 2018; W. Zhang et al. 2019).

The relationship of TC genesis with large-scale environmental conditions has been studied since the late 1940s, which was summarized recently in Emanuel (2018). First, Palmén (1948) showed using surface data and soundings that Atlantic hurricanes typically form over ocean with temperatures above $27^{\circ} \mathrm{C}$ and within $5^{\circ}$ latitude of the equator, in regions that are conditionally unstable, while in other regions and/or seasons the tropics are typically stable. Then, Gray (1979) developed an empirical relationship between genesis and climatological conditions of the environment, identifying six environmental conditions necessary for genesis: ocean thermal energy, low-level relative vorticity, vertical wind shear, Coriolis parameter, relative humidity of the troposphere, and a measure of instability of the atmosphere. Since then, many other empirical genesis indices have been developed (DeMaria et al. 2001; Emanuel and Nolan 2004; Emanuel 2010; Tippett et al. 2011; Bruyère et al. 2012; Camargo et al. 2014), making improvements and modifications on the original predictors by Gray. These modifications include using potential intensity instead of sea surface temperature (SST) (Emanuel and Nolan 2004; Emanuel 2010), determining a threshold effect for vorticity (Tippett et al. 2011), considering the saturation deficit of the midtroposphere instead of relative humidity (Emanuel 2010; Camargo et al. 2014), and adding the vertical velocity as an additional predictor (Murakami and Wang 2010). More recently, Tang and Emanuel (2012a,b) proposed a ventilation index combining humidity, shear, and potential intensity and have shown that it influences both genesis and intensification of TCs. Furthermore, Emanuel (2000), Wing et al. (2007), and Kossin and Camargo (2009) showed a relationship between observed TC intensity and potential intensity, supporting the inclusion of potential intensity in TC indices.

Given this rich history of relating environmental conditions to TC genesis and intensification, it is not surprising that when analyzing the climatology of TCs in climate models, the scientific community would make the assumption that there is a relationship between the model environmental fields climatology and the TC climatology in the model. We might expect these relationships to be valid in models, because they are valid in observations. Furthermore, if we look at the geographic and temporal variability within a single dataset (either model or observations/reanalysis), there is indeed a clear relationship between the model environment and TC activity. For example, genesis indices are typically able to reproduce the global climatological TC pattern, as well the seasonal and interannual variability in individual TC basins in observations (Camargo et al. 2007a; Tippett et al. 2011) and models (Camargo et al. 2007b; Camargo 2013; Camargo et al. 2014, 2016). Therefore, typically biases in modeled TC climatology are explained in the literature through the bias in the climatology of the large-scale environmental conditions in these models (Manganello et al. 2012; Camargo et al. 2016).

However, we are not aware of a study that shows that this hypothesis is actually valid. In fact, Reed et al. (2015) and Vecchi et al. (2019) showed that the TC activity in two versions of the same model could not be explained by the differences in their large-scale environment. In Reed et al. (2015) the model differences were due to different dynamical cores, whereas in Vecchi et al. (2019) they are due to different horizontal resolutions. Nevertheless, Vecchi et al. (2019) found that the responses in the models of different resolution could be reconciled after accounting for the sensitivity of pre-TC synoptic disturbances to changing climate, in addition to changes in large-scale environmental factors. We do know that if there are changes in the environment within a given model, due to climate variability or climate change, that the TC activity will change accordingly; this is why there is skill in dynamical seasonal forecasts (Camargo and Barnston 2009; Vitart 2009; Vecchi et al. 2014), for instance. Therefore, if we examine one specific model, generally there is a geographical and/or temporal relationship of the large-scale enviroment and TC activity. It is not obvious that this relationship actually leads to a coherent relationship across many models between the models' mean climatogical conditions and the models' TC climatology. If such a relationship existed, it would help explain the large differences in TC climatology characteristics among models.

While increasing model horizontal resolution is known to improve the ability of climate models to simulate TCs (Murakami and Sugi 2010; Manganello et al. 2012, 2014; Walsh et al. 2013; Strachan et al. 2013; Wehner et al. 2014; Roberts et al. 2015, 2018), resolution alone is not a solution for model biases. Models with the same or very similar horizontal resolution can have very different TC climatology characteristics (Camargo 2013; Shaevitz et al. 2014). 
It has been shown that besides resolution, the TC climatology in climate models is sensitive to model physics (Vitart et al. 2001; Reed and Jablonowski 2011; Kim et al. 2012; Murakami et al. 2012a; Zhao et al. 2012; Duvel et al. 2017), dynamical core (Reed et al. 2015), and coupling to the ocean (Zarzycki 2016; Scoccimarro et al. 2017; Li and Sriver 2018), as well as the tracking algorithm used to identify TCs in the model outuput (Horn et al. 2014; Zarzycki and Ullrich 2017). It is clear that complex processes in the model determine the formation and intensification of TCs.

Therefore, it is important to analyze the role of the climatological large-scale environment in determining the model TC climatology. The question we explore here is: do models with a climatological large-scale environment that is more conducive to TC genesis and intensification (e.g., higher values of potential intensity and lower values of vertical wind shear) have a TC climatology with more frequent and intense TCs? Similarly, if a model climatological environment is drier than other climate models, is this model's TC climatology less active than other models? These are simple questions, but they have not been explored systematically across multiple models.

We will consider 30 climate model simulations of TCs, from three multimodel ensembles, spanning a variety of models' horizontal resolution, physics, and dynamical core, as well as TC tracking algorithms. There are 14 model simulations from phase 5 of the Coupled Model Intercomparison Project (CMIP5) (Taylor et al. 2012), 6 from the U.S. CLIVAR Hurricane Working (HWG) (Walsh et al. 2015) dataset, and 10 model simulations from a collaborative effort for a NOAA funded project that is part of the NOAA Model Diagnostics Task Force (MDTF) (Maloney et al. 2019). Similarly to what was done in the analysis of the TCs in the HWG project (Shaevitz et al. 2014; Daloz et al. 2015; Nakamura et al. 2017; Ramsay et al. 2018), we are considering the tracking provided by each modeling group as part of the model package.

This is an ensemble of opportunity; that is, we use the model simulations and TC tracks that are available to us, as they are. These model simulations were not produced for this purpose. Therefore, there are caveats in our analysis that we need to be aware of, such as the dependence on the models' TC tracking schemes and thresholds. Our assumption is that if there are significant differences among the models' climatologies, these would be larger than those due to tracking scheme. As discussed in Horn et al. (2014), the sensitivity to differences in TC tracking schemes is more important for low-resolution models and weak storms; as the model resolution increases, the sensitivity to tracking routine decreases. We note that in most of the 30 models, with the exception of three cases, one of two tracking algorithms was used to track TCs. The TCs in all lowresolution models were tracked with the same tracking routine, so differences among them arise from other sources. This should help mitigate some of the tracking sensitivity in our analysis. Another issue that we should be aware of is that the model simulations in these multimodel ensembles do not consider the same periods and have different lengths. Furthermore, the CMIP5 multimodel ensemble consists of coupled ocean-atmospheric simulations (CMIP5) and in the other two ensembles, the simulations are forced with fixed SST. Finally, the HWG simulations are forced with climatological SST (i.e., the same SST for every year of the simulation varying only monthly), while the NOAA-MDTF simulations are forced with yearly varying monthly SST.

We will examine the climatological environmental fields that are typically associated with TC genesis and intensification among these models and determine if there is a robust relationship across models between the TC climatology and these environmental fields.

In section 2, we list the model simulations and data used in our analysis, as well as the large-scale environmental fields considered. Our results are given in section 3 , and the conclusions in section 4 .

\section{Models, data, and diagnostics}

\section{a. Models}

The models used in this analysis are from three different multimodel ensembles. The first set of models is from CMIP5 multimodel ensemble. The TCs in the historical coupled simulations (1850-2005) of 14 lowresolution models have been tracked using the CamargoZebiak algorithm (Camargo and Zebiak 2002), with the same thresholds globally. One ensemble member was used for each model. We only considered the period 1971-2000 so that we have a similar period and number of years as the observations and other multimodel ensembles. Various aspects of the TC activity in those simulations have been discussed in detail in Camargo (2013), as well as in Tang and Camargo (2014), Kossin et al. (2016), and Nakamura et al. (2017). Table 1 has a list of the CMIP5 models analyzed, including their references, resolution, and here are referred to as $\mathrm{C} 1$ to $\mathrm{C} 14$.

The second set of models is from the U.S. CLIVAR Hurricane Working Group (HWG) multimodel ensemble simulations for the current climate. Details about the HWG models and simulations are described in Walsh et al. (2015). The models in this ensemble have higher horizontal resolution $\left(0.25^{\circ}\right.$ to $\left.1.25^{\circ}\right)$ and were all forced with the same fixed climatological SST for the present 
TABLE 1. List of CMIP5 models analyzed, including their references, horizontal resolution, and name convention used. TCs are tracked in the historical simulations in the period 1971-2000 using the Camargo-Zebiak tracking routine (Camargo and Zebiak 2002) for one ensemble for each model, as described in Camargo (2013).

\begin{tabular}{lccl}
\hline \multicolumn{1}{c}{ Model } & Name & Resolution & \multicolumn{1}{c}{ Reference } \\
\hline CanESM2 & C1 & $2.9^{\circ}$ & von Salzen et al. (2013) \\
CCSM4 & C2 & $1.2^{\circ}$ & Gent et al. (2011) \\
CSIRO-Mk3.6.0 & C3 & $1.9^{\circ}$ & Rotstayn et al. (2012) \\
FGOALS-g2 & C4 & $3.0^{\circ}$ & Bao et al. (2013) \\
GFDL-CM3 & C5 & $2.5^{\circ}$ & Donner et al. (2011) \\
GFDL-ESM2M & C6 & $2.5^{\circ}$ & Donner et al. (2011) \\
HadGEM2-ES & C7 & $1.9^{\circ}$ & Jones et al. (2011) \\
INM-CM4.0 & C8 & $2.0^{\circ}$ & Volodin et al. (2010) \\
IPSL-CM5A-LR & C9 & $3.7^{\circ}$ & Voldoire et al. (2013) \\
MIROC-ESM & C10 & $2.8^{\circ}$ & Watanabe et al. (2011) \\
MIROC5 & C11 & $1.4^{\circ}$ & Watanabe et al. (2010) \\
MPI-ESM-LR & C12 & $1.9^{\circ}$ & Zanchettin et al. (2013) \\
MRI-CGCM3 & C13 & $1.2^{\circ}$ & Yukimoto et al. (2012) \\
NorESM1-M & C14 & $2.5^{\circ}$ & Zhang et al. (2012) \\
\hline
\end{tabular}

climate for the period (1985-2001). Various aspects of these simulations have been discussed in the literature (e.g., Shaevitz et al. 2014; Horn et al. 2014; Wang et al. 2014; Scoccimarro et al. 2014; Villarini et al. 2014; Daloz et al. 2015; Camargo et al. 2016; Han et al. 2016; Nakamura et al. 2017; Ramsay et al. 2018). Table 2 has a list of the HWG models, their resolution, and references, and they are called W1 to W6 in this manuscript. Only the models that had all the output necessary for our analysis were included here. Each modeling group contributed a different number of years for this project, varying from 10 to 20 years. All available years were considered in our analysis.

The third set of models is a contribution to our project as part of the NOAA Model Diagnostics Task Force (MDTF; Maloney et al. 2019). Various modeling groups agreed to contribute their existing simulations to this effort. Subsets of these simulations have been used for developing and testing process-oriented diagnostics for tropical cyclones in climate models, as described in
Kim et al. (2018), Wing et al. (2019), and Moon et al. (2020). These models typically have resolutions of $0.5^{\circ}$ and $0.25^{\circ}$, with exception of the model simulations that were performed for the MDTF $\left(1^{\circ}\right)$. Note that the HiRAM simulations that are part of this group were originally a contribution for the HWG, but with observed monthly varying SST. The list of the models in this group is given in Table 3 and they are named P1-P10. The CAM5-SE simulations used a variable-resolution grid, with resolution of $0.25^{\circ}$ in the North Atlantic and $1^{\circ}$ in the rest of the globe.

Note that the GISS-C180 employs a development version of GISS ModelE3 from early 2018 with a resolution of $0.5^{\circ}$. The dynamical core used in this study (Putman and Lin 2007) is the same as that used in GISS ModelE2. The parameterizations in this version of the model were also used by Cesana et al. (2019), who outline some updates to the physics distinguishing E3 from E2. Stratiform hydrometeors in E3 evolve within the two-moment microphysics framework of Gettelman and Morrison (2015), and water cloud fraction and cloud water mixing ratio are both diagnosed from a triangular probability density function. The turbulence model is based on Bretherton and Park (2009). The moist convection scheme retains the overall E2 structure but incorporates numerous updates to downdrafts, entrainment, and microphysics, and now features cold pools (Del Genio et al. 2015).

As mentioned above, the model simulations were not designed for this analysis, but rather we are using as many models as possible in it. For each case, we used the model output of as many years of the simulation as they were available to us, and the TC tracking routine that was used by each modeling group. This way we are considering the model and tracking routine as a package. It should be emphasized though that all low-resolution and two high-resolution models (C1-C14, W4, P7, P8, and P9) have been tracked with the Camargo-Zebiak tracking algorithm. Furthermore, most of the high-resolution models are tracked with the Vitart/Zhao algorithm,

TABLE 2. HWG models' characteristics, references for models and tracking schemes, and number of simulation years in each scenario. Definitions: LR: low resolution, HR: high resolution. References: Camargo and Zebiak: Camargo and Zebiak (2002), Prabhat: Prabhat et al. (2012), Rienecker: Rienecker et al. (2008), Roeckner: Roeckner et al. (2003), Saha: Saha et al. (2014); Schmidt: Schmidt et al. (2014); Scoccimarro: Scoccimarro et al. (2011), Vitart: Vitart et al. (2003), Wehner: (Wehner et al. 2015), Zhao: Zhao et al. (2009).

\begin{tabular}{lccll}
\hline \multicolumn{1}{c}{ Model } & Name & Resolution & \multicolumn{1}{c}{ Reference } & Tracking scheme \\
\hline CAM5.1 HR & W1 & $0.25^{\circ}$ & Wehner & Vitart/Prabhat \\
CAM5.1 LR & W2 & $1^{\circ}$ & Wehner & Vitart/Prabhat \\
CMCC-ECHAM5 & W3 & $0.75^{\circ}$ & Rockner/Scoccimarro & Vitart/Zhao \\
GISS C90 & W4 & $1^{\circ}$ & Schmidt & Camargo and Zebiak \\
NASA-GSFC & W5 & $0.5^{\circ}$ & Rienecker & Vitart/Zhao \\
NCEP-GFS & W6 & $1^{\circ}$ & Saha & Vitart/Zhao \\
\hline
\end{tabular}


TABLE 3. List of the NOAA process diagnostics models analyzed, including references, their horizontal resolution, and tracking routines. Camargo and Zebiak: Camargo and Zebiak (2002), Cherchi: Cherchi et al. (2019), Delworth: Delworth et al. (2012), Gent: Gent et al. (2011); Molod: Molod et al. (2015), Murakami: Murakami et al. (2015), Neale: Neale et al. (2012), Rienecker: Rienecker et al. (2008); TempestExtremes: Ullrich and Zarzycki (2017), Vecchi: Vecchi et al. (2014), Vitart: Vitart et al. (2003), Wehner: Wehner et al. (2014), Zarzycki:Zarzycki et al. (2014, 2017), Zhao: Zhao et al. (2009), Zhao18: Zhao et al. (2018a,b).

\begin{tabular}{|c|c|c|c|c|c|c|}
\hline Model & Name & Resolution & Reference & Tracking & Type & No. of years \\
\hline GFDL AM2.5-AMIP & $\mathrm{P} 1$ & $0.5^{\circ}$ & Delworth & Murakami & SST & 20 \\
\hline GFDL CM2.5-FLOR & $\mathrm{P} 2$ & $0.5^{\circ}$ & Vecchi & Murakami & Coupled & 20 \\
\hline GFDL HiRAM & P3 & $0.5^{\circ}$ & Zhao & Zhao/Vitart & SST & 20 \\
\hline CMCC-CAM5 & $\mathrm{P} 4$ & $0.25^{\circ}$ & Scoccimarro/Cherchi & Zhao/Vitart & SST & 5 \\
\hline CAM5-FV & P5 & $0.25^{\circ}$ & Neale/Wehner & Zhao/Vitart & SST & 20 \\
\hline CAM5-SE & P6 & $0.25^{\circ} 1^{\circ}$ & Neale/Zarzycki & TempestExtremes & SST & 20 \\
\hline GFDL AM4-MDTF & P7 & $1^{\circ}$ & Zhao18 & Camargo and Zebiak & SST & 5 \\
\hline CCSM4-MDTF & P8 & $1^{\circ}$ & Gent & Camargo and Zebiak & SST & 5 \\
\hline NASA GEOS5 & P9 & $0.5^{\circ}$ & Rienecker/Molod & Camargo and Zebiak & SST & 20 \\
\hline GISS-C180 & $\mathrm{P} 10$ & $0.5^{\circ}$ & Schmidt & Zhao/Vitart & SST & 20 \\
\hline
\end{tabular}

or a slight modification of this algorithm, namely five Hurricane Working Group models (W1, W2, W3, W5, and W6) and four process-oriented diagnostic models (P3, P4, P5, and P10). Only three models are not tracked with either of these algorithms: P1, P2, and P6. To explore the sensitivity of our results to the tracking algorithm, we will show in the online supplement a few key figures grouped by tracking algorithm.

\section{b. Data}

We compare the models' environmental fields with those produced by the European Centre for MediumRange Weather Forecasts (ECMWF) interim reanalysis (ERA-Interim) dataset (Dee et al. 2011), which is available from 1979 to the present. Here we consider the period 1981-2010 for the climatology, as it has the largest overlap with all the models' climatology.

The TC observations are based on the best track datasets of the National Hurricane Center (NHC) for the Atlantic and eastern North Pacific (Landsea and Franklin 2013) and the Joint Typhoon Warning Center (JTWC) (Chu et al. 2002) for the other basins. The best track datasets from these two agencies were chosen, as they have consistent time averaging of $1 \mathrm{~min}$ for the maximum wind speed. We consider the observations in the period 1981-2010. We also consider TCs tracked in the ERA-Interim reanalysis using the Murakami and Sugi (2010) tracking method, as described in Murakami et al. (2014) for the period 1981-2010. Similarly to reanalysis, this period was chosen due to the largest overlap across all models.

\section{c. Diagnostics}

We use two diagnostics to represent the TC climatology: the number of TCs (NTC) and the accumulated cyclone energy (ACE). We only consider TCs that form in the tropics $\left(30^{\circ} \mathrm{S}-30^{\circ} \mathrm{N}\right)$. For observations, we consider only TCs that reach at least tropical storm intensity (i.e., surface wind speeds of at least $17 \mathrm{~m} \mathrm{~s}^{-1}$ ). In contrast, for the models we did not use an additional threshold in the storm's intensity, as it is standard to have thresholds in the models' tracking schemes, which are typically dependent on the models' horizontal resolution (Walsh et al. 2007). In the models we excluded storms that form in the South Atlantic and southeast Pacific (east of $250^{\circ}$ ), as they are not present in either the NHC or the JTWC observed datasets in that period. Furthermore, we want to match the environmental fields to $\mathrm{TC}$ formation areas and the environmental conditions in those regions are not conducive to TC activity and would bias our results.

ACE is defined as $\Sigma v^{2}$ for all 6-hourly time steps, where $v$ is the maximum sustained surface wind speed. In observations, only time steps for which the surface winds reach at least $35 \mathrm{kt}$ are included in the ACE calculation, following the definition of Bell et al. (2000). For the models, we used a modified version, including the wind speed at all time steps, as in Camargo (2013). This is particularly important in the case of low-resolution models, which generate very weak storms. Furthermore, Davis (2018) showed that from a dynamical perspective, $0.25^{\circ}$ (the finest resolution considered here) should not produce a realistic number of category 4 and 5 storms in the absence of larger wind radii or suplementary parameterization. Zarzycki and Ullrich (2017) showed that integrated quantities as ACE are less sensitive to differences in tracking algorithms than TC counts. The reason for that is that all trackers are typically able to track the most intense long-lived storms, which contribute most significantly to ACE. Therefore, our analysis of ACE has smaller uncertainty due to track sensitivity than NTC.

Track density is calculated by counting the number of TCs passing in each grid point in the 6-hourly tracks. For each model, the track density is normalized by the 
number of simulation years. The track density was calculated using a common grid for models and observations, namely a uniform $4^{\circ}$ grid.

We examined various standard environmental fields that are typically used to determine if the environment is conducive for TC formation and intensification; in particular, the components of genesis indices (Gray 1979; Emanuel and Nolan 2004; Emanuel 2010; Tippett et al. 2011; Camargo et al. 2014) and the ventilation index (Tang and Emanuel 2012b,a), as well one genesis index combining several fields together. All these variables were computed from monthly-mean fields in models and observations. We only show a subset of the analyzed fields here. They are as follows:

- Vertical shear: magnitude of the vertical wind shear between 200 and $850 \mathrm{hPa}$

- Relative humidity at $600 \mathrm{hPa}$

- Column relative humidity: ratio of the column integrated water vapor path and the column saturated water vapor path (Bretherton et al. 2004; Camargo et al. 2014)

- Omega at $500 \mathrm{hPa}$

- Relative vorticity at $850 \mathrm{hPa}$

- Potential intensity (PI): theoretical maximum intensity that a TC can reach based on the local thermodynamics conditions, as defined in (Emanuel 1988), following the calculations of Bister and Emanuel (2002).

- Tropical cyclone genesis index (TCGI): empirical genesis index following the formulation of Tippett et al. (2011) and Camargo et al. (2014).

This formulation of TCGI was chosen due to facilitate a comparison with NTC, as the integrated value of TCGI gives the predicted NTC by the index. This is not the case for most genesis indices. Furthermore, Menkes et al. (2012) have shown that TCGI has a performance similar to or even superior to other genesis indices. The climatology of all environmental variables is calculated using either 30 years or all years available if the number of years is smaller than 30 . When we integrate the environmental variables we consider only the ocean grid points, in the Northern Hemisphere tropics $\left(0^{\circ}-30^{\circ} \mathrm{N}\right)$ for the months of August to October (ASO) and in the Southern Hemisphere tropics $\left(30^{\circ} \mathrm{S}-0\right)$ for the months of January to March (JFM). As in the case of NTC and ACE, we exclude the South Atlantic and the southeast Pacific (east of $250^{\circ} \mathrm{E}$ ) in our analysis. Similarly, the biases in the models' environmental field climatologies relative to the ERA-Interim climatology are quantified using two measures: spatial correlation and root-meansquare error. These quantities are calculated for each model and environmental variable, in the tropical region of each hemisphere in their respective TC season
(ASO and JFM) over the ocean. The high-resolution models (P and $\mathrm{W})$ and ERA-Interim are interpolated to a common uniform $1^{\circ}$ grid for these calculations. A similar interpolation is performed for the low-resolution models (C), but using a $2^{\circ}$ uniform grid instead.

\section{Results}

\section{a. Models, TC climatology}

To give an overview of the models, TC climatology, Figs. 1 and 2 show the first position and the tracks for 5 years (minimum number of years available across all models) for the models, reanalysis, and observations. For the models that have more than 5 years of simulation available, the years were chosen as to have the maximum overlap among the models. Figure 3 shows the track density, using all years available in each case (varying from 5 to 30 years) using a grid box of size of $4^{\circ}$ for all models. It is clear from Figs. 1-3 that many low-resolution models $(\mathrm{C} 1-\mathrm{C} 14)$ have a very unrealistic climatology of TC-like storms, with very few storms and in many cases no TC-like storms in some basins, especially in the Atlantic. This is not restricted to the CMIP5-type models; these strong biases are still present in some of the HWG (e.g., W2, W6) and MDTF models (e.g., P8), all of which have $1^{\circ}$ resolution. Furthermore, in observations the TC activity in the Southern Hemisphere is about half of the Northern Hemisphere, and many models do not reproduce this difference.

These model biases can be seen in more detail in the distributions of NTC and ACE per year for all models, reanalysis, and observations shown in Fig. 4. It is clear that the models in the HWG (W1-W6) and and MDTF (P1-P10) ensembles simulate a number of TCs much closer to observations than the CMIP5 models. The exception of the HWG models is W2, which used the observed threshold for defining TCs in that model (Wehner et al. 2015), while other models of the same resolution use a resolution-dependent threshold (Walsh et al. 2007). Some of the high-resolution models actually produce too many storms compared with observations, in particular P2, P3, and W5. In contrast, most models and the reanalysis have ACE values that are too low compared with observations, indicating that their TCs are too weak, which could be expected based on their horizontal resolution (Davis 2018). The only exceptions are $\mathrm{P} 4, \mathrm{P} 5$, and $\mathrm{W} 1$, which have a bias toward high values of ACE. These three models are different versions of the CAM5 model at $0.25^{\circ}$, which indicates some specific characteristic of this particular model that leads to strong storms. Various studies (Zarzycki 2016; Scoccimarro et al. 2017; Li and Sriver 2018) showed that this bias can be 

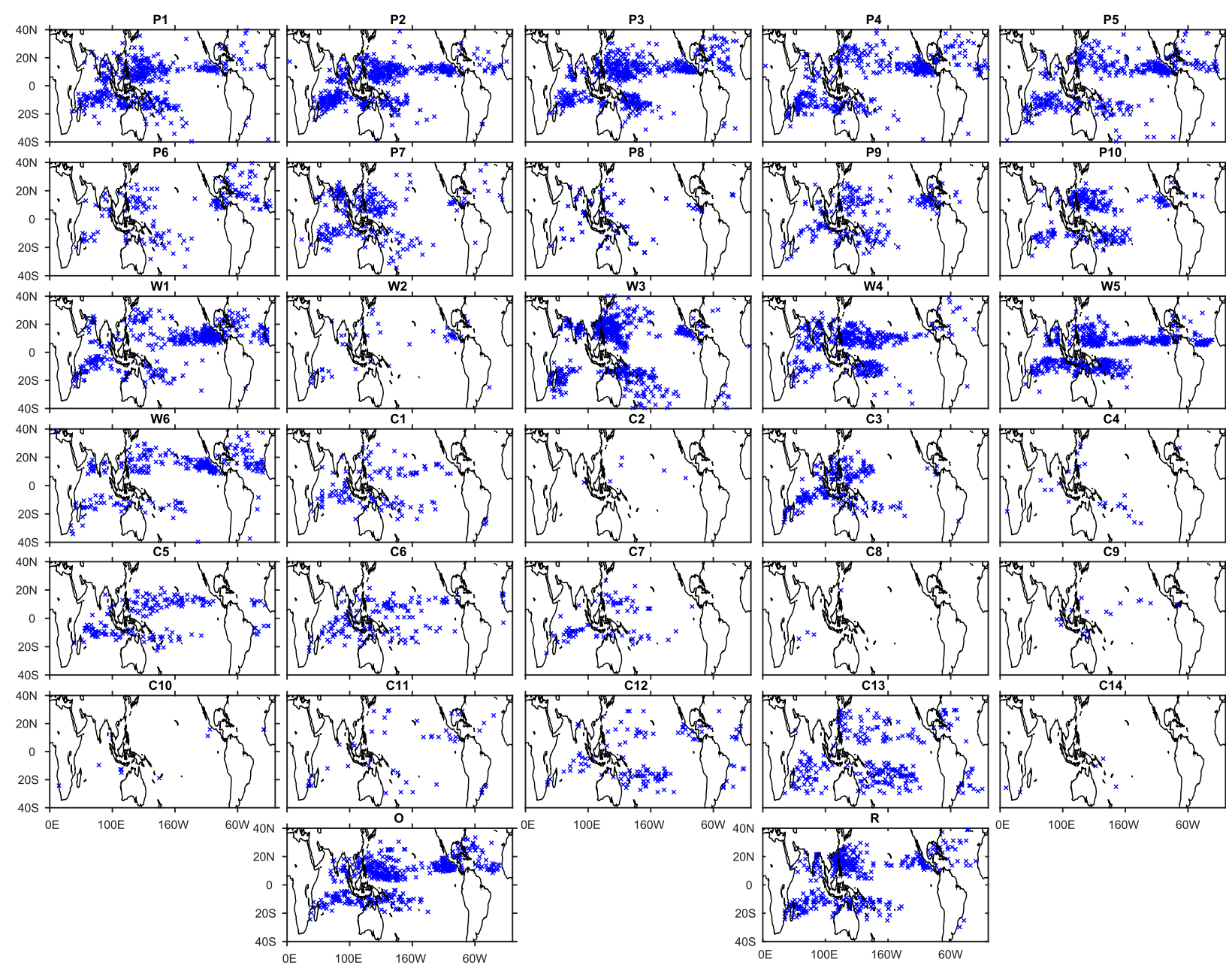

FIG. 1. Five years of first position locations of TC-like storms in models (P1-P10, W1-W6, C1-C14), reanalysis $(R)$, and observations $(O)$. Data for the years 1991-95 were used for reanalysis, observations, and models C1-C14 and P1-P10, if available. In the case of W1-W6 the first five consecutive years were considered.

improved by coupling the atmospheric model to an ocean model, instead of using fixed SSTs.

\section{b. Dependence on horizontal resolution}

The first point we examine is how the models' TC climatology is dependent on model horizontal resolution. Figure 5 shows scatterplots between NTC and ACE with model horizontal resolution for the tropics and by hemisphere. There is some dependence of NTC on model resolution, with higher values of NTC and ACE as the the model horizontal resolution increases. This relationship is stronger for models with resolution finer than $1^{\circ}$. In contrast, for low-resolution models there is a much weaker relationship between NTC and ACE and model resolution. However, despite some resolution dependence, models with the same resolution can have very different values of NTC, with a substantial spread among models with the same resolution, for either low-resolution (e.g., models with $2^{\circ}$ ) or highresolution (e.g., models with $0.5^{\circ}$ ) models. The spread can be large for ACE as well, especially across highresolution models. If we separate NTC and ACE by hemisphere (Figs. 5c-f), there is a similar behavior in both hemispheres. While most high-resolution models are able to replicate the observed behavior of a higher level of TC activity in the Northern Hemisphere than in the Southern Hemisphere, this is not the case for low-resolution models, which have similar levels of activity in both hemispheres. (Note that Fig. S4 in the online supplemental material is similar to Figs. $5 \mathrm{c}-\mathrm{f}$, but instead of separating the models by resolution, the models are separated by tracking routine. Both figures are very similar, showing that this analysis is not sensitive to the tracking algorithm used.)

Figure 6 shows scatterplots of high percentiles of TC maximum surface wind speed with resolution. These are computed for all model TCs in the Northern Hemisphere 

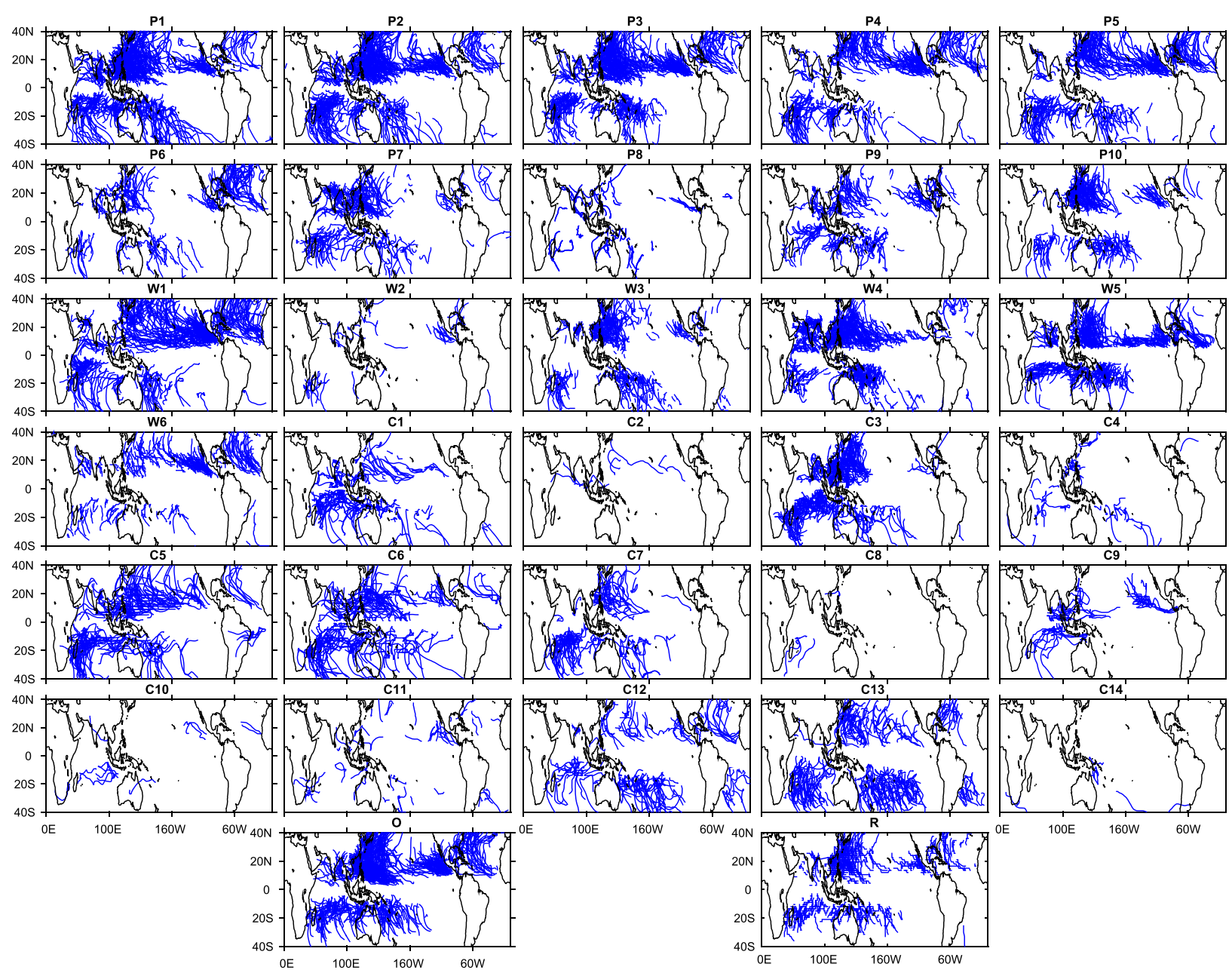

FIG. 2. Five years of tracks of TC-like storms in models (P1-P10, W1-W6, C1-C14), reanalysis $(R)$, and observations $(O)$. Data for the years 1991-95 were used for reanalysis, observations, and models C1-C14 and P1-P10, if available. In the case of W1-W6 the first five consecutive years were considered.

tropics in ASO. The values of the 99th, 95th, and 90th percentiles of the distribution for each model are shown. The 99th percentile regression line is the steepest one in the top panel, showing a stronger dependence on resolution for the most intense storms in low-resolution models. Similarly to what was already noted for NTC and ACE, models with similar resolution can have very different values of maximum wind speed, making clear that resolution is not the only factor that determines how intense the models' TCs can be.

\section{c. Environmental fields}

We now examine the biases in the climatology of the models' environmental fields associated with TC activity. Figures 7-9 show the anomalies of the vertical shear, relative humidity at $600 \mathrm{hPa}$ and PI compared with ERA-Interim climatology, which is also shown in all figures. The anomalies in the Northern Hemisphere are calculated in ASO and in the Southern Hemisphere in JFM.

There is large range in the anomalies of the models for the vertical shear (Fig. 7). While some models have very small biases across the globe, such as P2, P3, and P6, others have large anomalies. P7 has large positive anomalies in the tropics, in particular near the date line. Furthermore, in many models the tropical Atlantic vertical shear is too strong (P4, P5, P7, W1, C7, C8, C9, C10, C12, and C13). In contrast, the vertical shear is too weak in the north Indian Ocean in a few models, in particular P4, W1, W2, W6, C10, and $\mathrm{C} 12$. It should be noted though that the north Indian Ocean has a minimum of TC activity in ASO due to the high wind shear associated with the Indian monsoon.

In the case of relative humidity (Fig. 8), the values in various models are too high across both hemispheres, such as P4, P7, P9, P10, W3, W5, C4, and C12. In contrast, other models tend to have negative biases in some regions and 


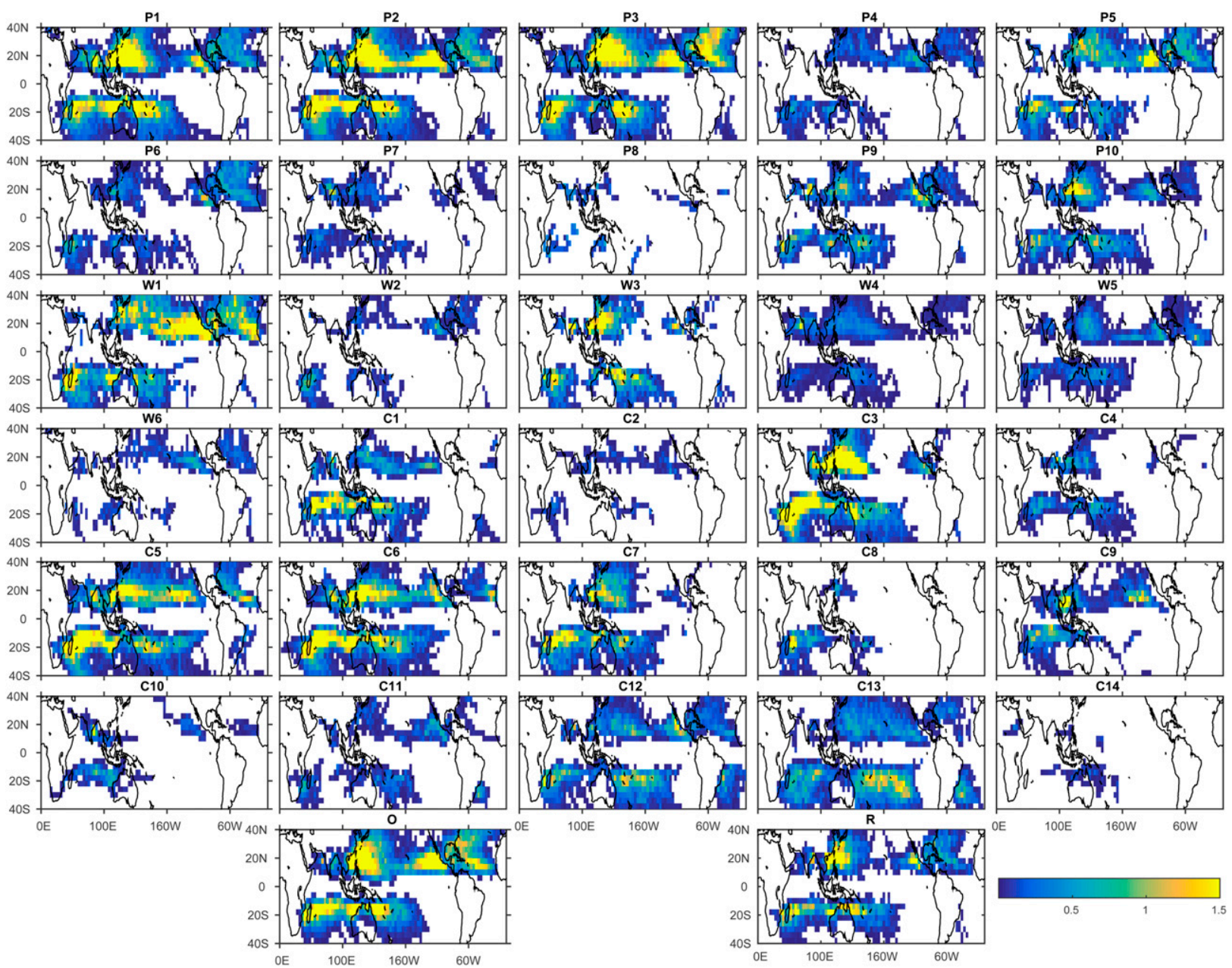

FIG. 3. Track density (mean of track passages per grid point) of TC storms in models (P1-P10, W1-W6, C1-C14), reanalysis $(R)$, and observations $(O)$ using all years available for each model (as shown in Tables 1-3). A common uniform grid of $4^{\circ}$ was used and normalized by the number of years available in each case.

positive in others (P3, W1, W6, C2, C5, C10). Many models have their largest biases in relative humidity in the equatorial region (P3, W1, W2, C2), in particular in the central Pacific.

Potential intensity (PI) anomalies are shown in Fig. 9. A few models' biases stand out in this case; while P4 PI is too high in both hemispheres, C12 PI is too low. In contrast, P5 and P6 have strong negative anomalies in the Northern Hemisphere only. Many CMIP5 models (C) show too strong values of PI in the eastern Pacific in both hemispheres $(\mathrm{C} 4, \mathrm{C} 5, \mathrm{C} 6, \mathrm{C} 8, \mathrm{C} 9, \mathrm{C} 10, \mathrm{C} 11, \mathrm{C} 12$, $\mathrm{C} 13$, and $\mathrm{C} 14)$. As this type of bias is not present in any of the models forced with fixed SST (most P models and $\mathrm{W}$ models), this bias is probably related to coupling.

For completeness we show similar plots for omega at $500 \mathrm{hPa}$, relative vorticity at $850 \mathrm{hPa}$, and TCGI in Figs $\mathrm{S} 1, \mathrm{~S} 2$, and S3 in the online supplemental material. In the case of Omega (Fig. S1), many P and W models have positive biases in the Indo-Pacific equatorial region, with exception of $\mathrm{P} 7$ and $\mathrm{P} 10$, which show negative biases in the same region. In contrast, the relative vorticity biases (Fig. S2) have dipole anomaly patterns in both hemispheres, indicative of a shift in location of the vorticity in the models. Models typically have positive biases in TCGI (Fig. S3) in the regions of maximum TC activity, and negative biases outside of that region.

In an attempt to quantify these results, Fig. 10 shows scatterplots of the spatial correlations and root-meansquare error (RMSE) of these environmental fields in both hemispheres (in the tropics and over the ocean), relative to the ERA-Interim reanalysis. It is clear across the panels that the CMIP5 (C) models typically have lower correlations and higher RMSE than the $\mathrm{P}$ and $\mathrm{W}$ models. This is not surprising, given that the $\mathrm{C}$ models have lower resolution and are coupled, which tend to lead to large biases. This is particularly true for the spatial correlations of relative humidity, potential intensity, and TCGI. 

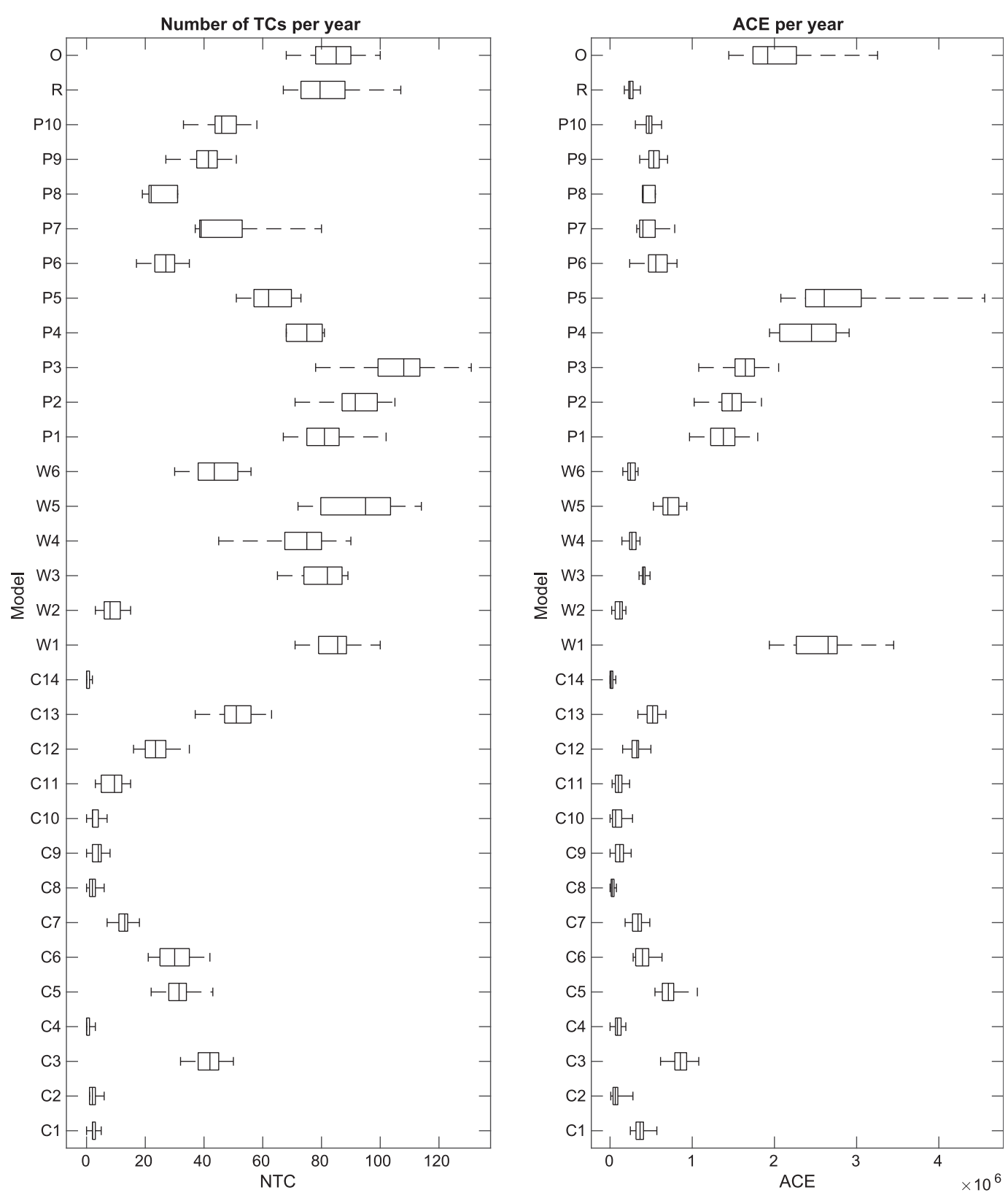

FIG. 4. Distributions of (a) NTC and (b) ACE per year distributions in models, reanalysis, and observations. Model labels are defined in Tables 1-3.

Another interesting result is that for both omega Fig. 10d and relative vorticity Fig. 10e, there is a clear separation for all model types by hemisphere, with lower RMSE in the Northern Hemisphere and higher in the Southern Hemisphere. Interestingly, the spatial correlation in the Northern Hemisphere reaches lower values than in the Southern Hemisphere.

While in the case of vertical shear Fig. 10a there is an almost linear relationship between RMSE and correlations, with low RSME values associated with high correlations, and the opposite for high RSME. However, this is not the case for other variables. In particular, for the relative humidity (Fig. 10b), many models have high spatial correlations, but a large range of RSME values, indicating that the models can replicate the reanalysis pattern well, but not its magnitude. This is also typically the case for TCGI (Fig. 10f) for $\mathrm{P}$ and $\mathrm{W}$ models, but not for all $\mathrm{C}$ models. While the $\mathrm{P}$ and $\mathrm{W}$ models have high correlations and low RMSE for PI (Fig. 10c), with exception of one 


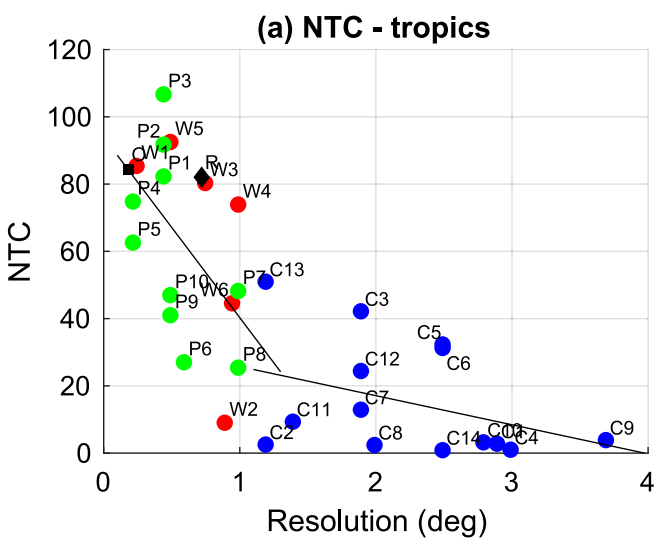

(c) NTC - Northern Hemisphere

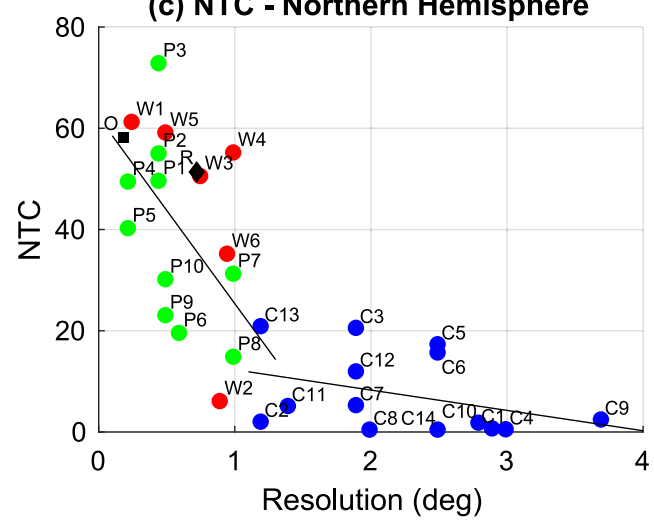

(e) NTC - Southern Hemisphere

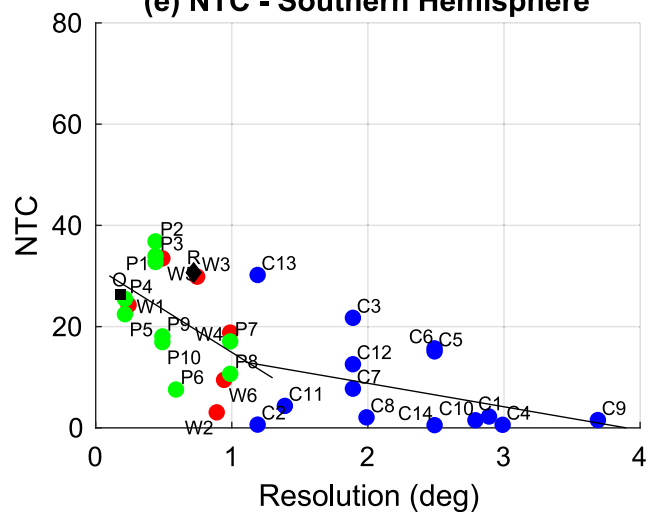

(b) ACE - tropics

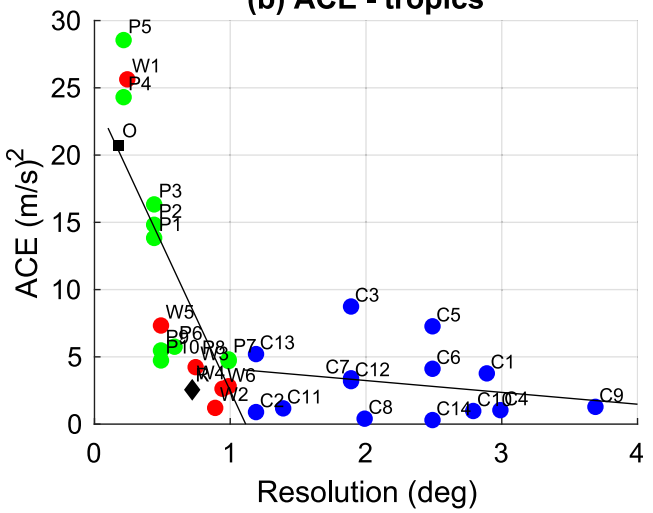

(d) ACE - Northern Hemisphere

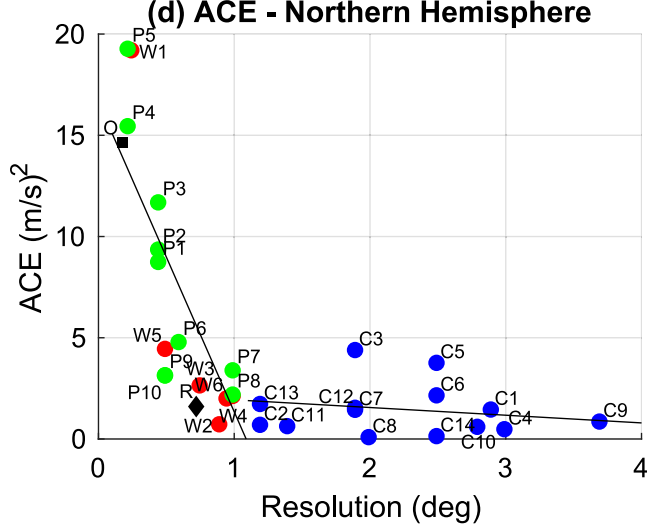

(f) ACE - Southern Hemisphere

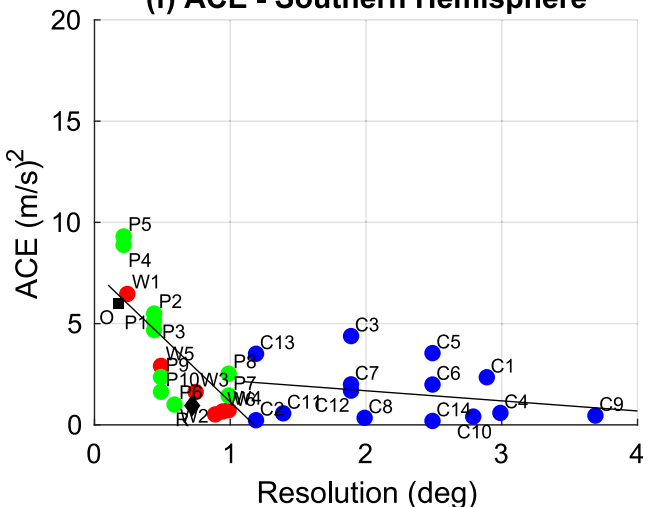

FIG. 5. Scatterplots of (a),(c),(e) NTC and (b),(d),(f) ACE vs model horizontal resolution in degrees. Models labels are defined in Tables 1-3. (top) The tropical mean, (middle) the Northern Hemisphere, and (bottom) the Southern Hemisphere; $C$ (CMIP5) models are shown in blue, $W$ (HWG) models in red, $P$ (process-oriented) models in green, and observations $(O)$ and reanalysis $(R)$ in black.

outlier, C models have much lower spatial correlations, probably related to the biases in the eastern Pacific noted above.

\section{d. Relationship of environmental fields and TC climatology}

We next examine whether there is a relationship between climatological environmental fields and climatological TC activity in the models - that is, if a model has a more conducive environment for TC formation and/or intensification, does it have more TCs or are there more TCs that reach higher intensity values?

To examine this question we integrated the climatological environmental fields in the tropics in the season of interest (ASO in the Northern Hemisphere, JFM in the Southern Hemisphere) for each model and related 
(a) Wind speeds percentiles - Low-resolution Models

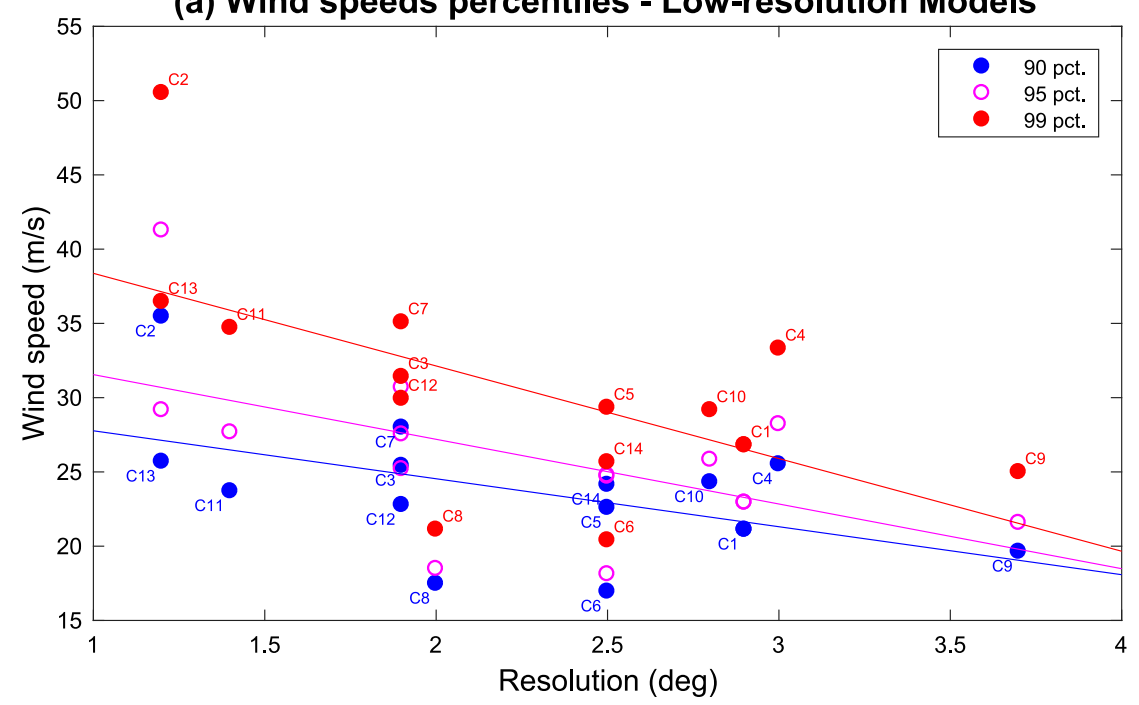

(b) Wind speeds percentiles - High-resolution Models

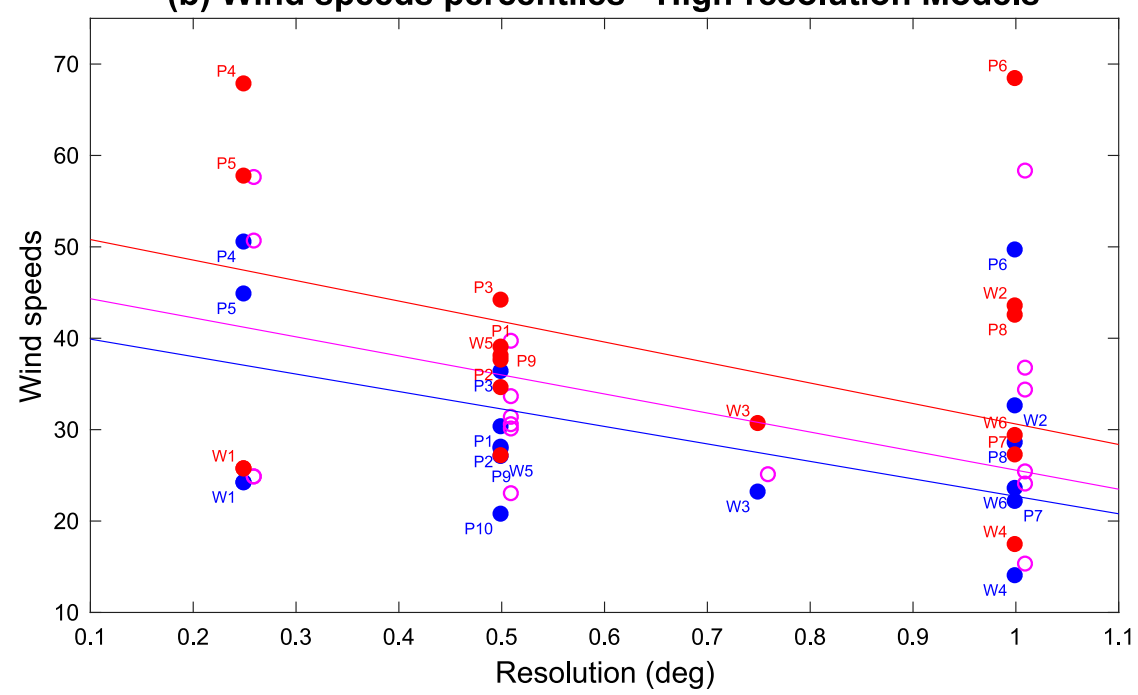

FIG. 6. Scatterplots of wind speeds percentiles (99\%, 95\%, and 90\%) vs model horizontal resolution in degrees for the Northern Hemisphere for (a) low-resolution and (b) highresolution models. Model labels are defined in Tables 1-3.

this to the corresponding NTC and ACE, as described in section 2. Given the very different range of values in NTC and ACE for low-resolution and high-resolution models, we split each scatterplot in two, one for low-resolution models (C models) and another for high-resolution models (W and P models). The resulting scatterplots for NTC are given in Figs. 11 and 12, for the Northern and Southern Hemisphere, respectively. Similar figures for ACE in each hemisphere are shown in Figs. 13 and 14. In each panel the linear fit and corresponding correlation coefficient are also shown.

Figures 11-14 make clear that there is no coherent relationship between the mean environmental conditions across the models and the mean TC climatology. For instance, large values of midlevel relative humidity are important for tropical cyclogenesis (Gray 1979; Emanuel and Nolan 2004). Nolan et al. (2007) and Rappin et al. (2010) found that reducing the free troposphere saturation deficit is critical for intensification. While low-resolution models with higher climatological relative humidity do generate more TCs in the Northern Hemisphere (Fig. 11a), that is not the case in the Southern Hemisphere (Fig. 12a), or for high-resolution models (Figs. 11b, and 12b) (actually, the opposite relationship is observed). Similarly, while there is a positive relationship between relative humidity and ACE in 

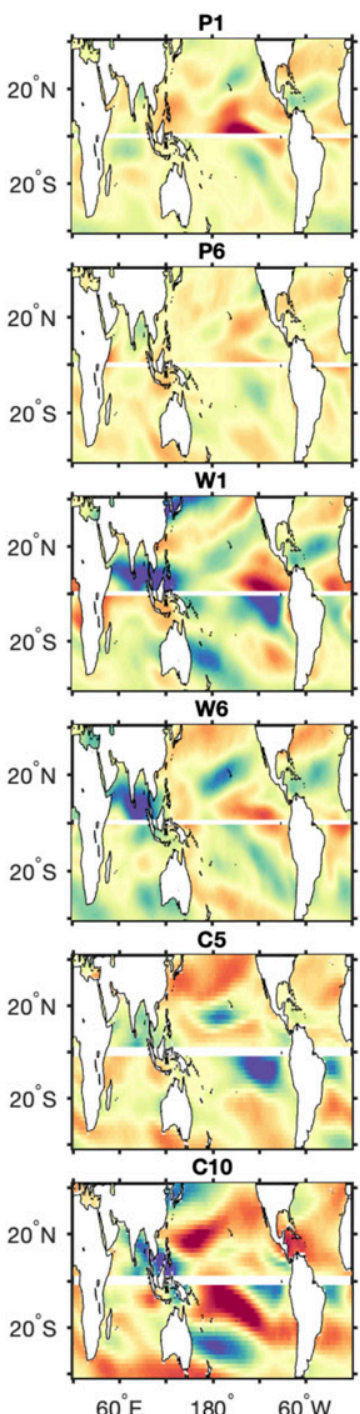
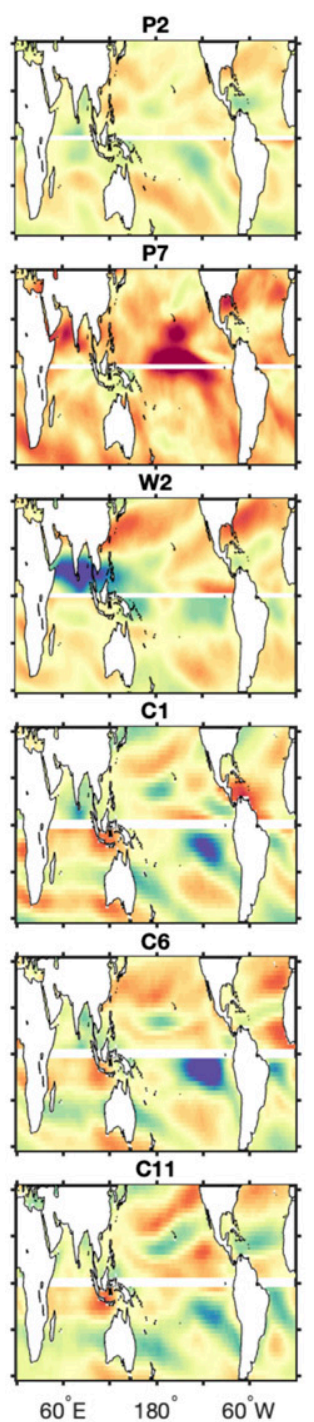
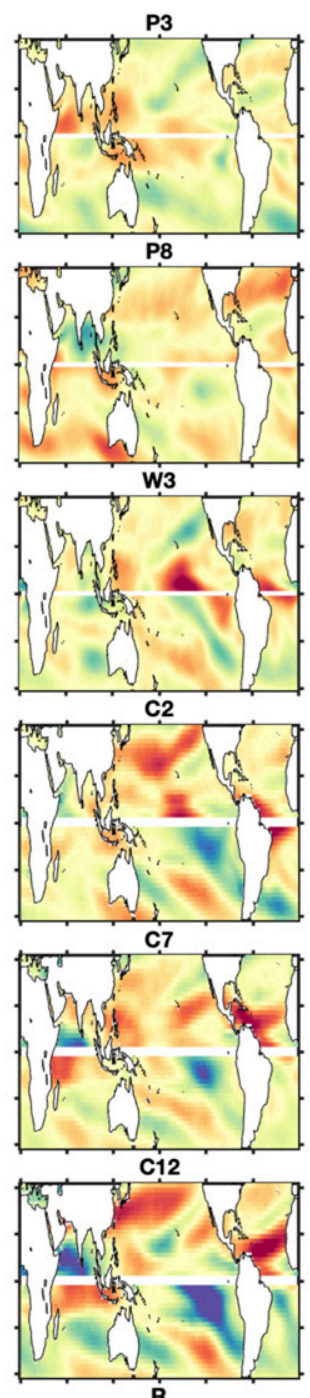

$20^{\circ} \mathrm{N}$
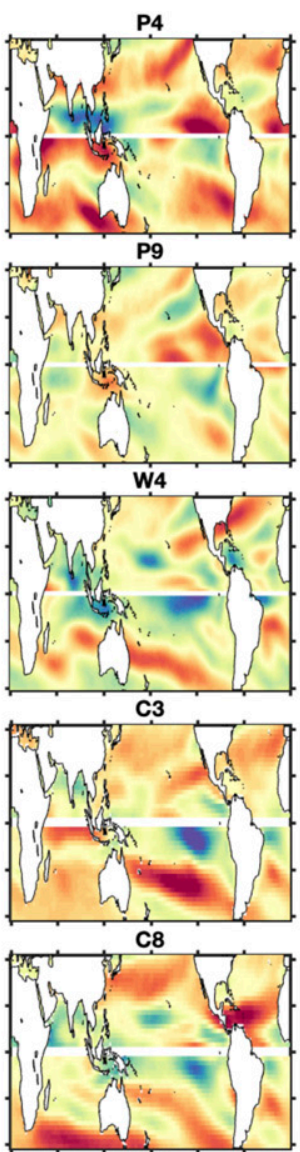

C13
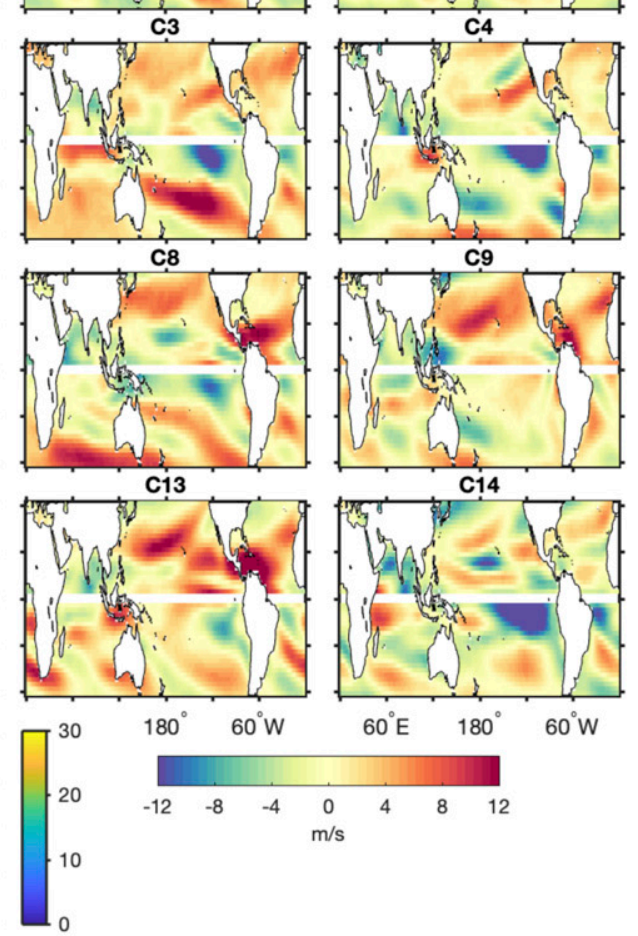
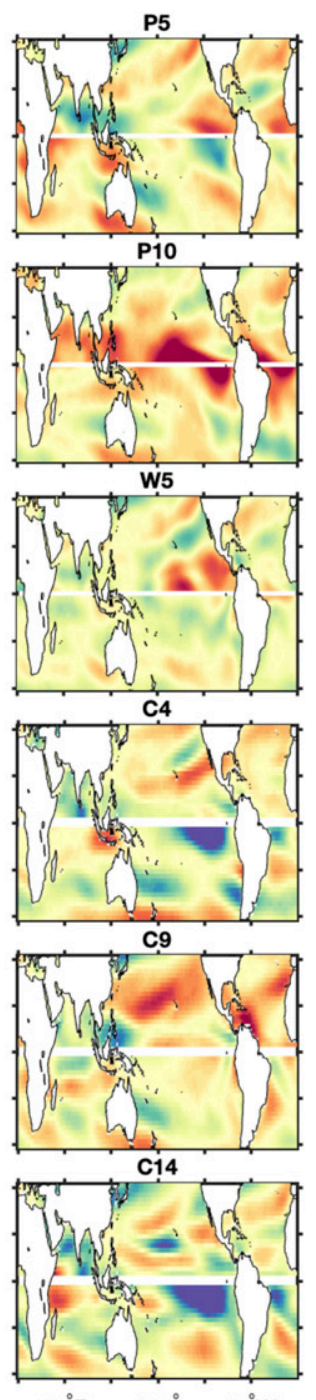

$60^{\circ} \mathrm{E} \quad 180^{\circ} \quad 60^{\circ} \mathrm{W}$

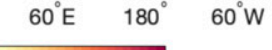

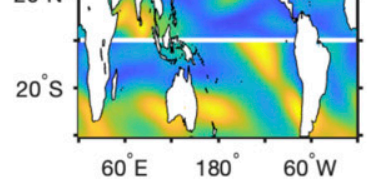

FIG. 7. Anomalies of vertical wind shear $\left(\mathrm{m} \mathrm{s}^{-1}\right)$ for all models $(\mathrm{C} 1-\mathrm{C} 14, \mathrm{~W} 1-\mathrm{W} 6, \mathrm{P} 1-\mathrm{P} 14)$ relative to the ERA-Interim reanalysis climatology $(R)$ : ASO in the Northern Hemisphere, JFM in the Southern Hemisphere.

both hemispheres for low-resolution models (Figs. 13a and 14a), this is not the case for high-resolution models (Figs. 13b and 14b). In Figs. 11-14 we only show our results using the midlevel relative humidity, but similar plots were obtained using saturation deficit and column relative humidity.

In the case of relative vorticity, we would expect a higher number of TCs for models with higher mean climatological relative vorticity values (Gray 1979; Emanuel and Nolan 2004), as these models potentially could have more disturbances that lead to more TCs. Tippett et al. (2011) showed that the relationship of relative vorticity to genesis has a threshold beyond which higher values of vorticity are not related to more frequent cyclogenesis. While there is a positive relationship with NTC and ACE in the Northern Hemisphere for low-resolution models (Figs. 11c and 13c) and for ACE for high-resolution models in the Northern Hemisphere (Fig. 13d), the opposite occurs for low-resolution models in the Southern Hemisphere for NTC and ACE (Figs. 12c and 14c) and 

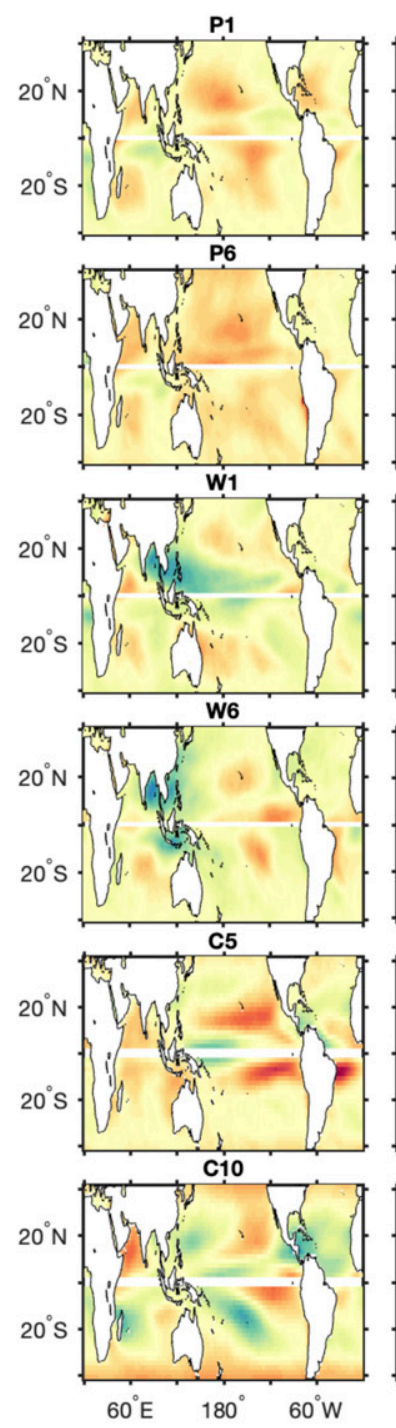
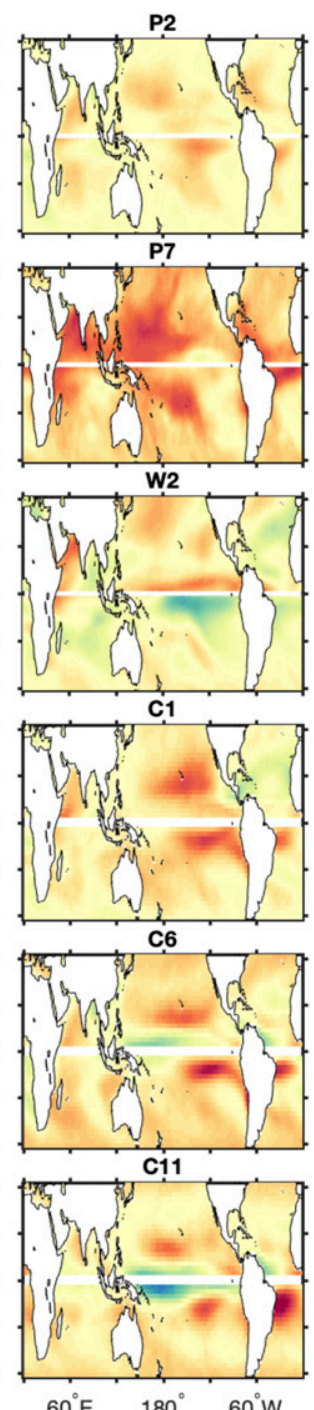

$60^{\circ} \mathrm{E} \quad 180^{\circ} \quad 60^{\circ} \mathrm{W}$
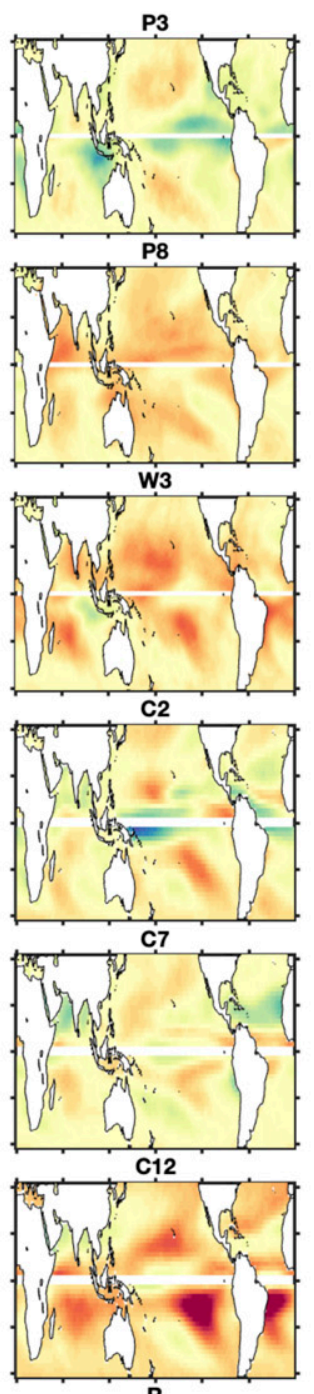

$20^{\circ} \mathrm{N}$
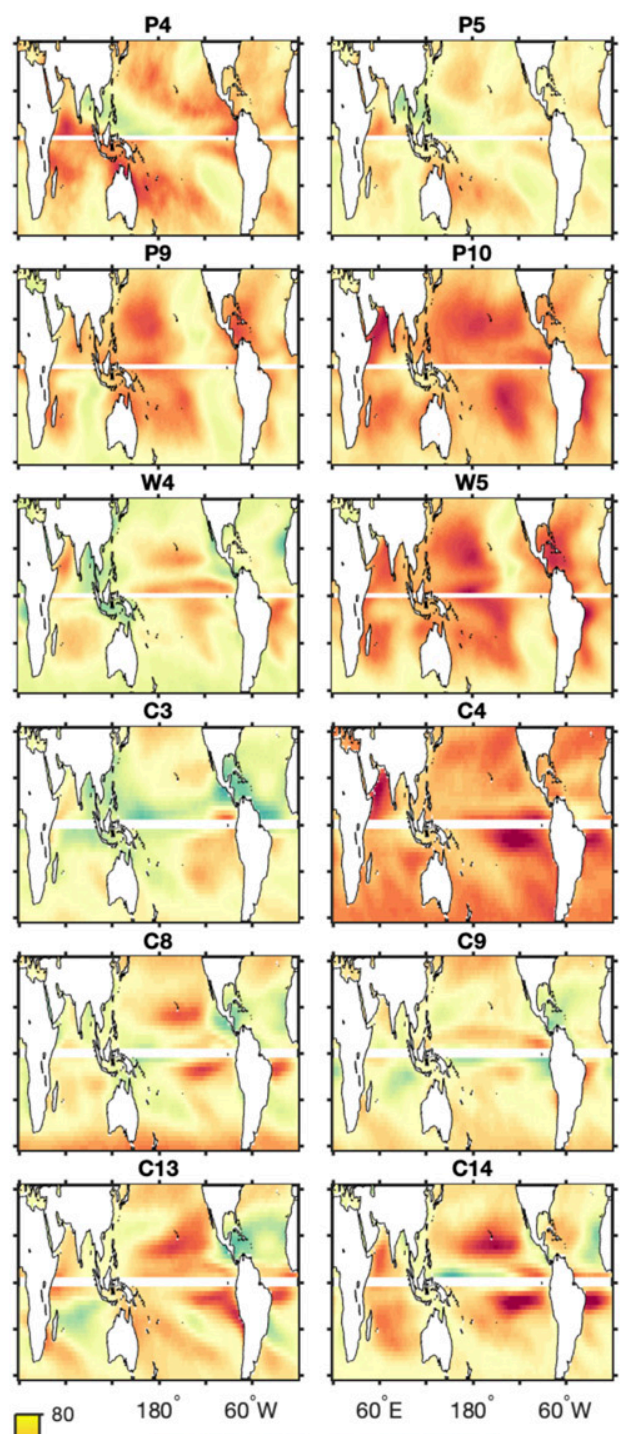

$60^{\circ} \mathrm{E} \quad 180^{\circ} \quad 60^{\circ} \mathrm{W}$
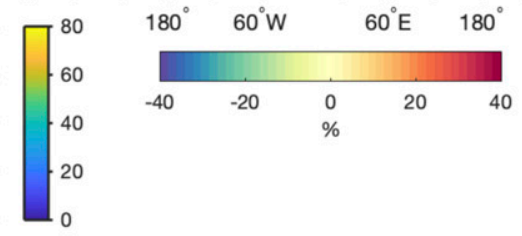

FIG. 8. Anomalies of relative humidity at $600 \mathrm{hPa}(\%)$ for all models (C1-C14, W1-W6, P1-P14) relative to the ERA-Interim reanalysis climatology $(R)$ : ASO in the Northern Hemisphere, JFM in the Southern Hemisphere.

for NTC in high-resolution models in the Southern Hemisphere (Fig. 12d), and there is no relationship at all in the other cases.

Vertical wind shear has a strong control on the climatology of TCs (Gray 1968), with developing storms tending to form under low values of vertical wind shear (McBride and Zehr 1981; Tang and Emanuel 2010). Large-scale vertical wind shear also tends to weaken tropical cyclones (DeMaria and Kaplan 1994; Tang and
Emanuel 2010). For the vertical wind shear [Figs. 11-14, panels (e) and (f)], there is a decrease in NTC and/or ACE with the magnitude of the climatological vertical wind shear, as expected. But the relationship is weak and in one case (Fig. 12e) the relationship is the opposite.

There is a strong relationship between observed TC intensity and PI (Emanuel 2000; Wing et al. 2007; Kossin and Camargo 2009), with higher values of PI corresponding 

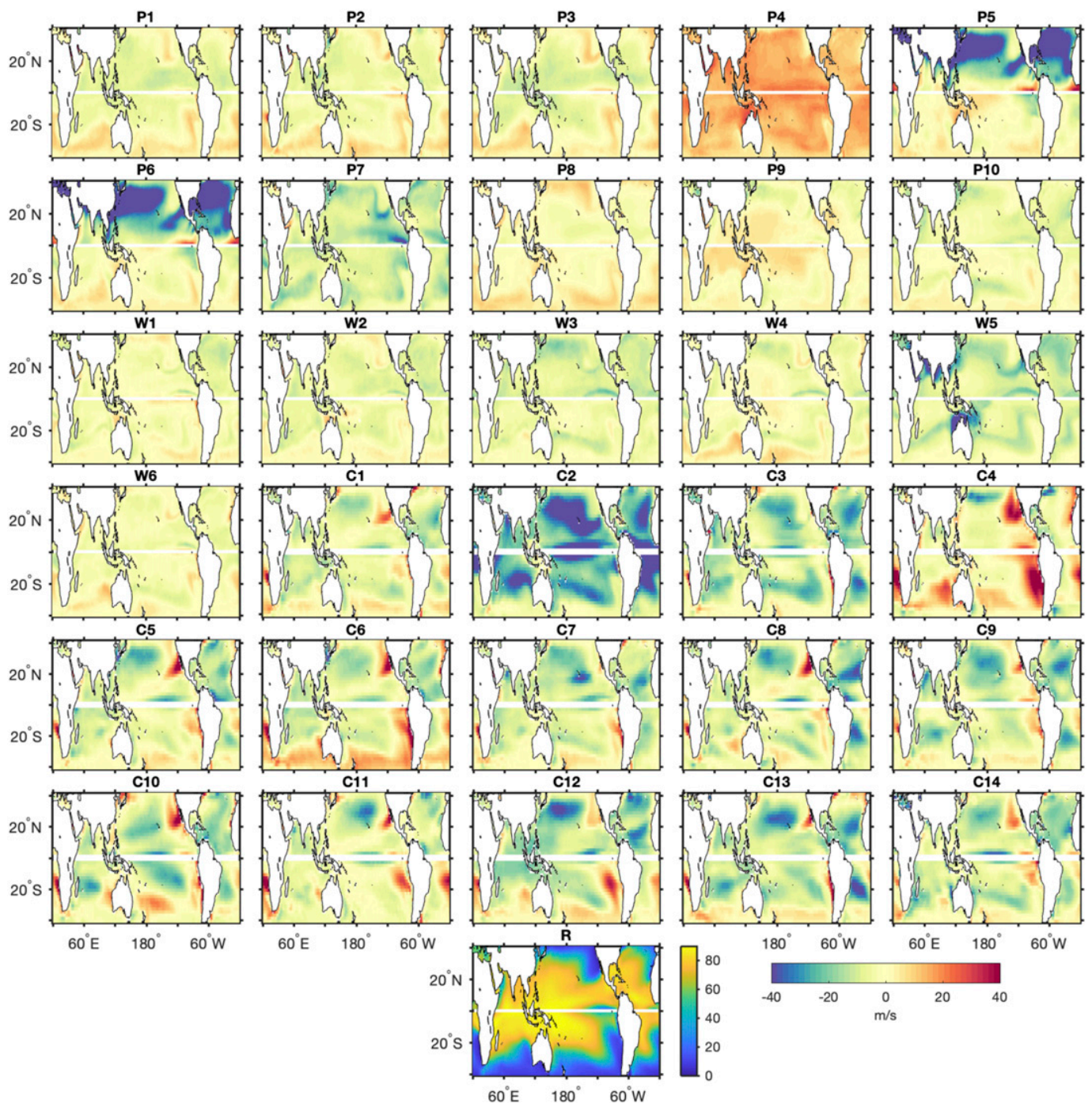

FIG. 9. Anomalies of potential intensity (PI) $\left(\mathrm{m} \mathrm{s}^{-1}\right)$ for all models $(\mathrm{C} 1-\mathrm{C} 14, \mathrm{~W} 1-\mathrm{W} 6, \mathrm{P} 1-\mathrm{P} 14)$ relative to the ERA-Interim reanalysis climatology $(R)$ : ASO in the Northern Hemisphere, JFM in the Southern Hemisphere.

to stronger TCs in a large range of time scales and spatial scales. Empirically, genesis is rarely observed for PI values below $40 \mathrm{~m} \mathrm{~s}^{-1}$ (Emanuel 2018) and PI is used in various genesis indices (Emanuel and Nolan 2004; Emanuel 2010; Camargo et al. 2014), as well as being one of the components of the ventilation index (Tang and Emanuel 2012a,b). While for low-resolution models there is a positive relationship between PI and NTC, and PI and ACE [Figs. 11-14, panels (g)], the same is not true for high-resolution models [panels (h)], with a decrease of NTC in the Northern Hemisphere and of ACE in both hemispheres, in contrast to observations.

Murakami and Wang (2010) added vertical velocity as an additional predictor to the Emanuel and Nolan
(2004) genesis index, arguing that a high frequency of TC genesis correspond to areas with large upward motion and that this vertical motion was not fully taken into account in the original genesis index. Zhao and Held (2012) explored the relationship of TC activity with various environmental variables using one of the climate models from our study (P3) and found that the strongest relationship was with vertical velocity at $500 \mathrm{hPa}$. Furthermore, the same authors argued in Held and Zhao (2011) that the atmospheric vertical mass flux can be useful in understanding the reduction of TC hurricane activity in their idealized climate change experiments. However, Camargo et al. (2014) did not find a coherent response of vertical velocity with this reduction in genesis in a perfect model experiment. 

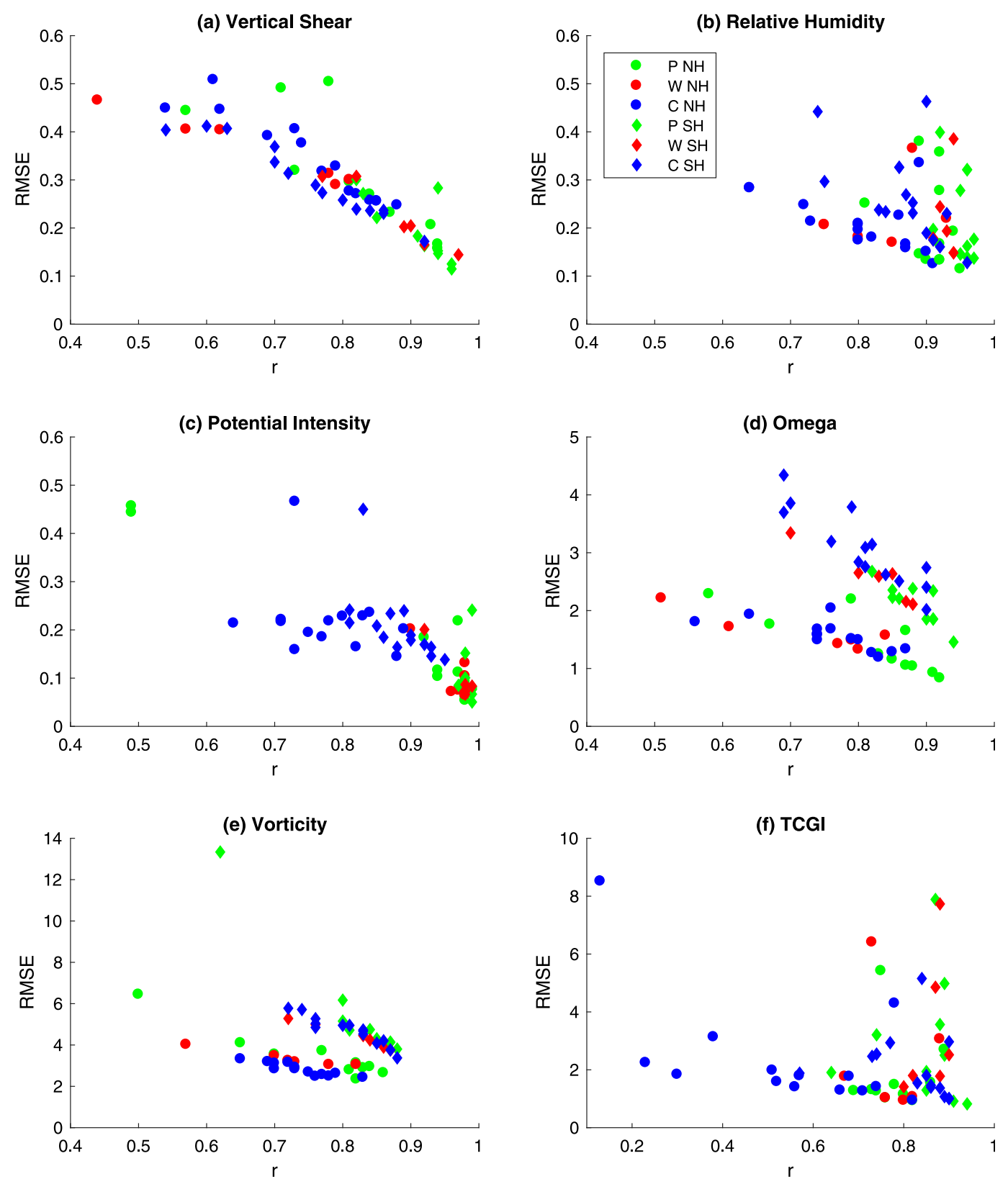

FIG. 10. Scatterplots of the values of the spatial correlation and root-mean-square error between the models and ERA-Interim reanalysis climatology of environmental variables [(a) vertical wind shear, (b) relative humidity at $600 \mathrm{hPa}$, (c) potential intensity, (d) omega at $500 \mathrm{hPa}$, (e) relative vorticity at $850 \mathrm{hPa}$, and (f) TCGI] over the ocean for ASO in the Northern Hemisphere $\left(0^{\circ}-30^{\circ} \mathrm{N}\right)$ and JFM in the Southern Hemisphere $\left(30^{\circ} \mathrm{S}-0^{\circ}\right)$. P1-P10 models are shown in green, W1-W6 models in red, and C1-C14 models in blue. Northern (Southern) Hemisphere values are shown in circles (diamonds). The root-mean-square errors are normalized by the mean value of the reanalysis climatology in the region and season considered.

Here we find a positive relationship between vertical velocity and TC activity diagnostics only for low-resolution models [Figs. 11-14, panels (i)], not for high-resolution models [Figs. 11-14, panels (j)].

We also show scatterplots of NTC and ACE with one genesis index, namely TCGI developed by Tippett et al. (2011). We performed the same analysis with other versions of this index, using other predictors, as discussed in Camargo et al. (2014) (not shown). Similar to other genesis indices (e.g., Camargo et al. 2005; Camargo 2013; Wehner et al. 2015), there is not a strong relationship between the model climatological 

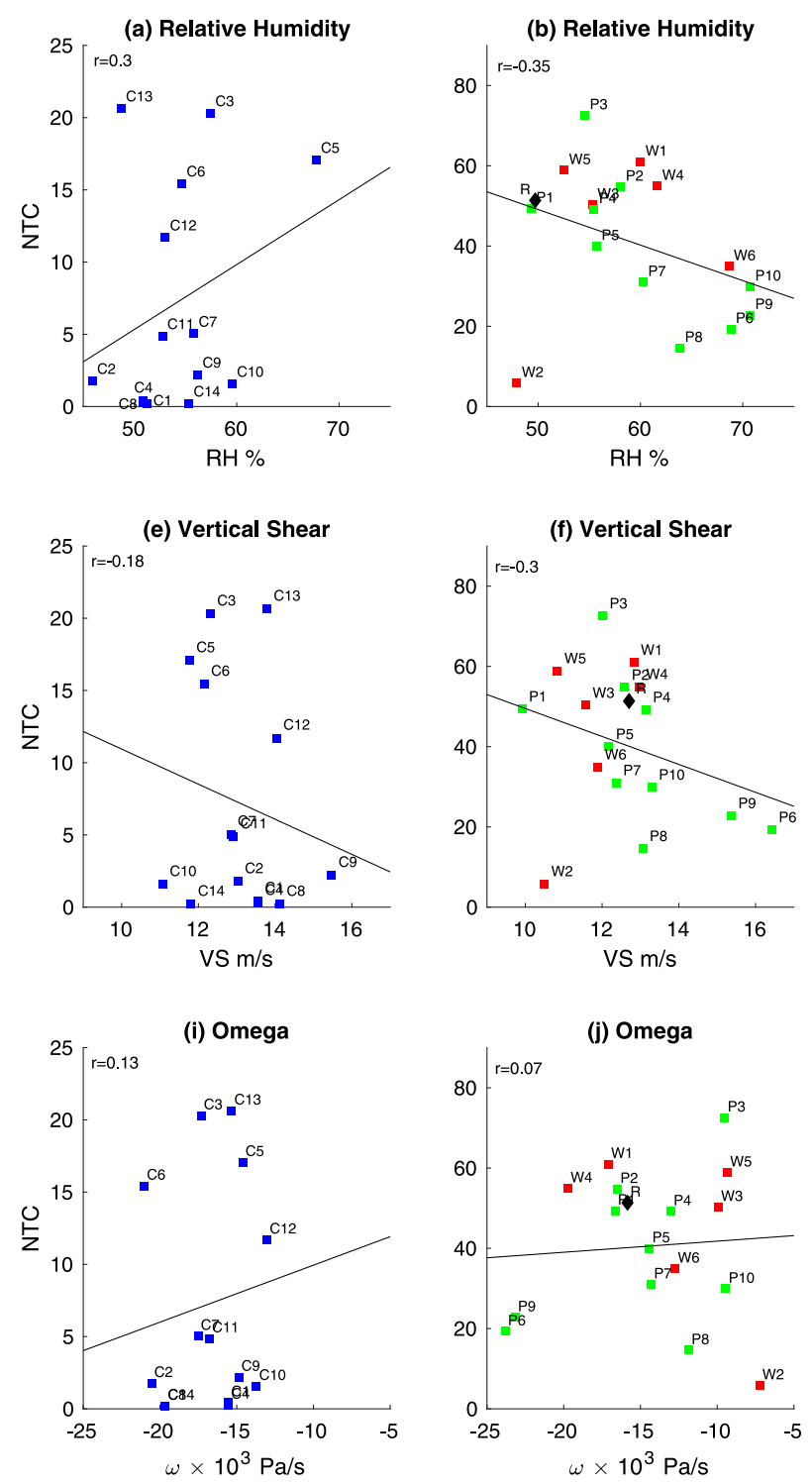
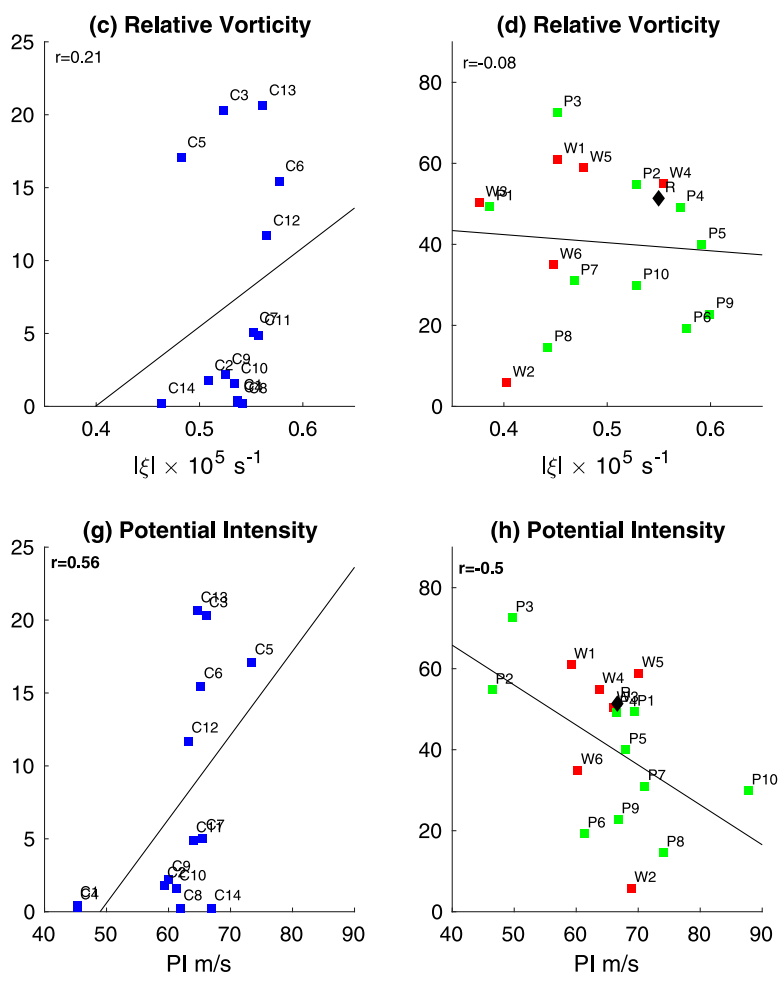

(k) TCGI

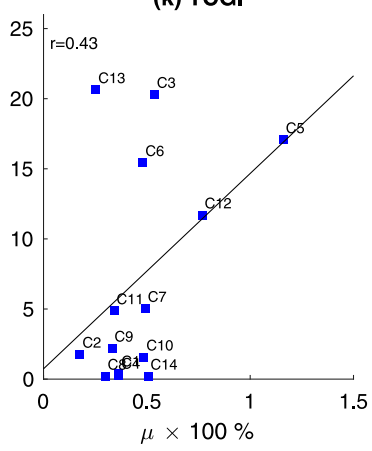

(I) TCGI

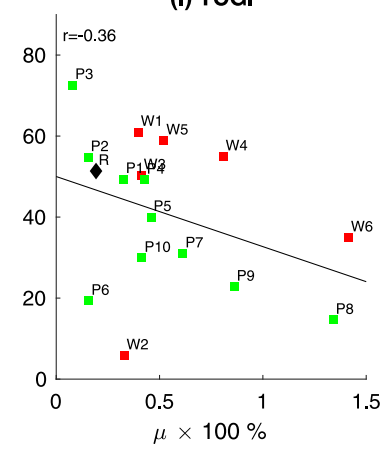

FIG. 11. Scatterplots of mean climatological NTC and environmental fields for the tropical Northern Hemisphere in ASO; $C$ (CMIP5) models are shown in blue, $W$ (HWG) models in red, $P$ (process-oriented) models in green, reanalysis $(R)$ in black. Statistically significance correlations at the 95th significance levels are shown in bold.

TC activity and the climatological values of these indices in the same models, although the relationship between NTC and genesis indices seemed to improve with horizontal resolution for a few models (Camargo et al. 2005). However, changes in TC activity due to climate variability (e.g., El Niño-Southern Oscillation or volcano activity) are indeed reflected in changes in these indices (Camargo et al. 2005; Pausata and Camargo 2019; Camargo and Polvani 2019). Overall, similar to other variables, we do not obtain a coherent response of the mean climatological TCGI across models in our analysis [Figs. 11-14, panels (k) and (l)].
To try to examine if the lack of a robust relationships between NTC and ACE is influenced by the models' resolution, we repeated this analysis for two different groups of models: in the first one, only models with resolution between $1.4^{\circ}$ and $0.75^{\circ}$ are considered, and in the second only models with resolution of $0.5^{\circ}$ or higher. The results (shown in Figs. S2S9) are very consistent with the ones shown above: there is no robust relationship between the environmental variables and NTC and ACE, even for models with similar resolutions and excluding models with unrealistic TC climatology. The only exception was found for models with resolution of $0.5^{\circ}$ and higher, in 

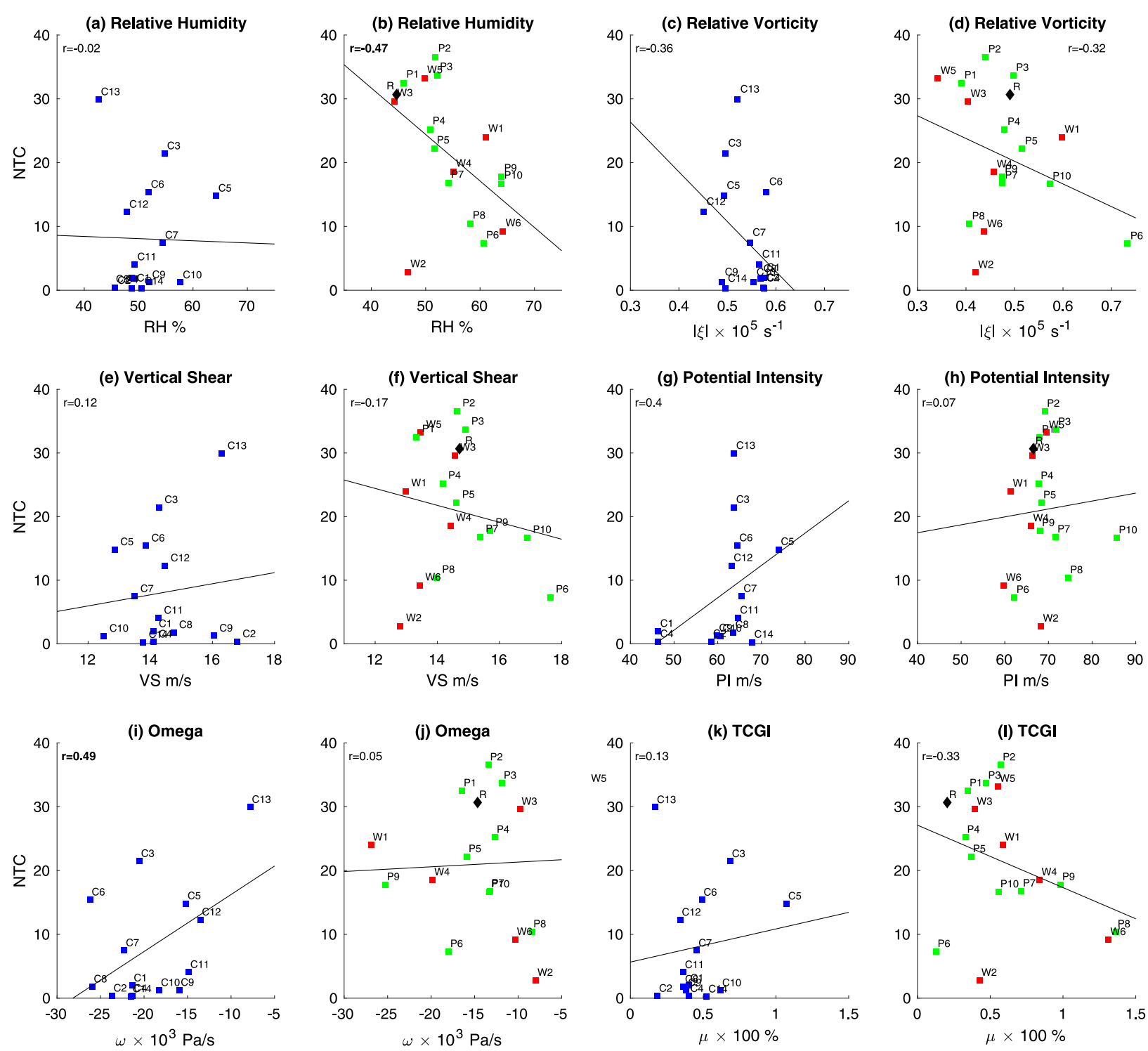

FIG. 12. Scatterplots of mean climatological NTC and environmental fields for the tropical Southern Hemisphere in JFM; $C$ (CMIP5) models are shown in blue, $W$ (HWG) models in red, $P$ (process-oriented) models in green, reanalysis $(R)$ in black. Statistical significance correlations at the 95 th significance levels are shown in bold.

which NTC and ACE decrease with increasing vertical shear and the relationship is significant in 3 of the 4 cases examined. We repeated this analysis grouping the analysis by tracking routine for the models tracked with either the Camargo-Zebiak or Zhao/Vitart tracking algorithms. The results are similar (Figs. S13-S16), with no robust relationship between the climatological environmental variables and NTC and ACE for these two tracking algorithms across resolutions. This is a good indication that our results are not sensitive to tracking routine used, especially in the case of ACE (Zarzycki and Ullrich 2017).

\section{Conclusions}

It is common in the literature to try to explain biases in climate models' TC climatology using biases in these models' environmental variables climatology. However, as far as we are aware there is no study that shows that such relationship is actually valid. Here we explore this relationship using 30 climate models from three different multimodel ensembles at various resolutions. We show that there is no coherent relationship between the mean state of these models, represented here by a large number of environmental variables usually associated 


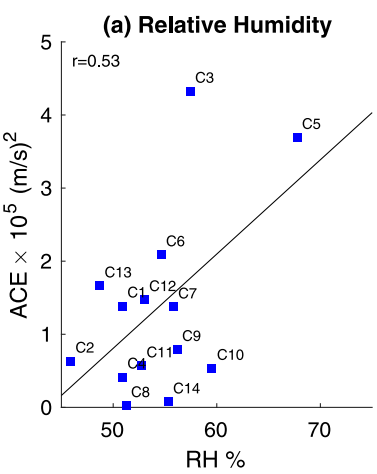

(e) Vertical Shear

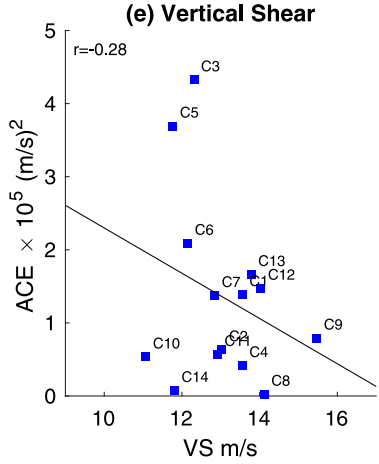

(i) Omega

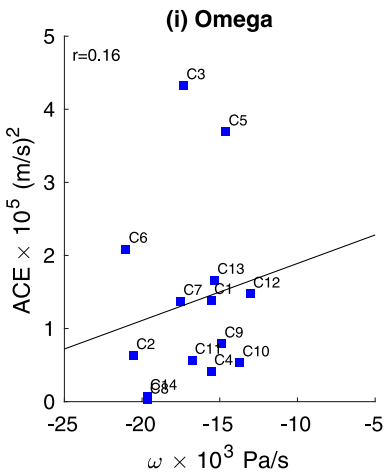

(b) Relative Humidity

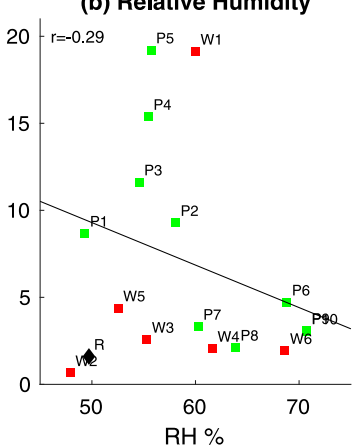

(f) Vertical Shear

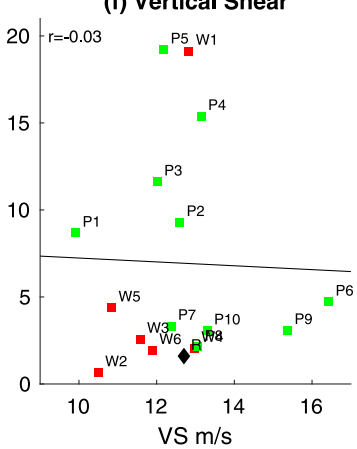

(j) Omega

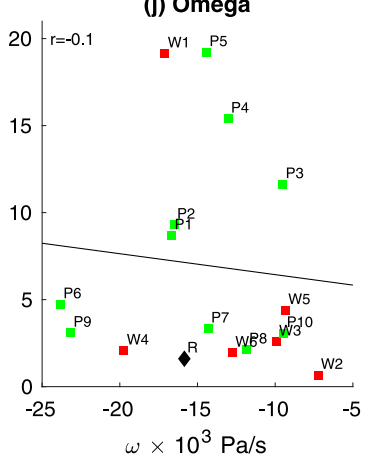

(c) Relative Vorticity

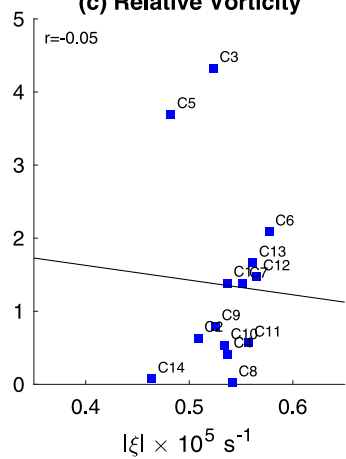

(g) Potential Intensity

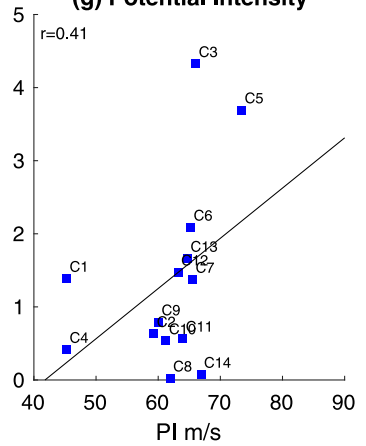

(k) TCGI

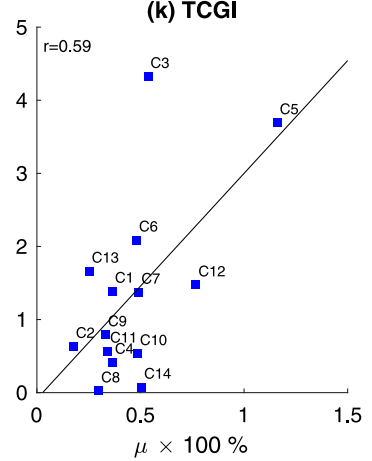

(d) Relative Vorticity

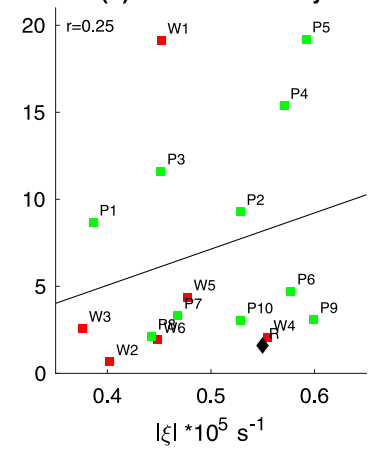

(h) Potential Intensity

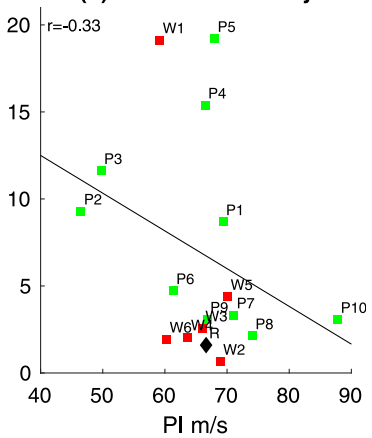

(I) TCGI

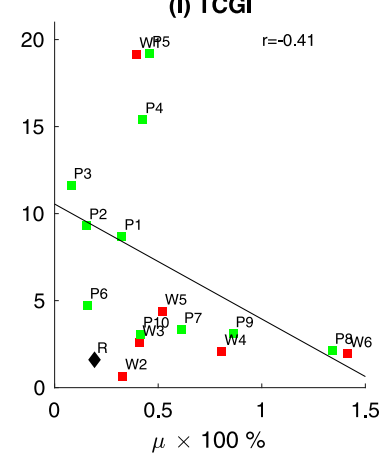

FIG. 13. Scatterplots of mean climatological ACE and environmental fields for the tropical Northern Hemisphere in ASO; $C$ (CMIP5) models are shown in blue, $W(\mathrm{HWG})$ models in red, $P$ (process-oriented) models in green, reanalysis $(R)$ in black. None of the correlations are statistically significant at the 95 th significance level.

with TC activity, and the mean TC model climatology. In particular, there is no universal relationship between the simulated large-scale environment and TC activity, as while there are some relationships between environment and TC activity in certain classes of models, these relationships are not consistent across all models. This lack of coherent relationship between the enviroment and TC activity occurrs even if only models with similar resolution are considered, and by excluding models with low-resolution and unrealistic TC climatology.

Our results are not surprising, given the large number of studies that explored the sensitivity of model TC climatology to various model characteristics (e.g., model physics, dynamical core, tracking methodology, etc.). However, given the widespread use of the largescale environmental fields as an explanation to models' TC biases, it is important to show that this standard practice is actually not valid. To understand model TC climatological biases more in-depth diagnostics are necessary, such as the process-based diagnostics developed by Kim et al. (2018), Wing et al. (2019), and Moon et al. (2020). Additional information may also be gained by working to understand of the response of pre-TC synoptic disturbances, or "TC seeds," in addition to the large-scale environmental impact on TC genesis (Vecchi et al. 2019). 

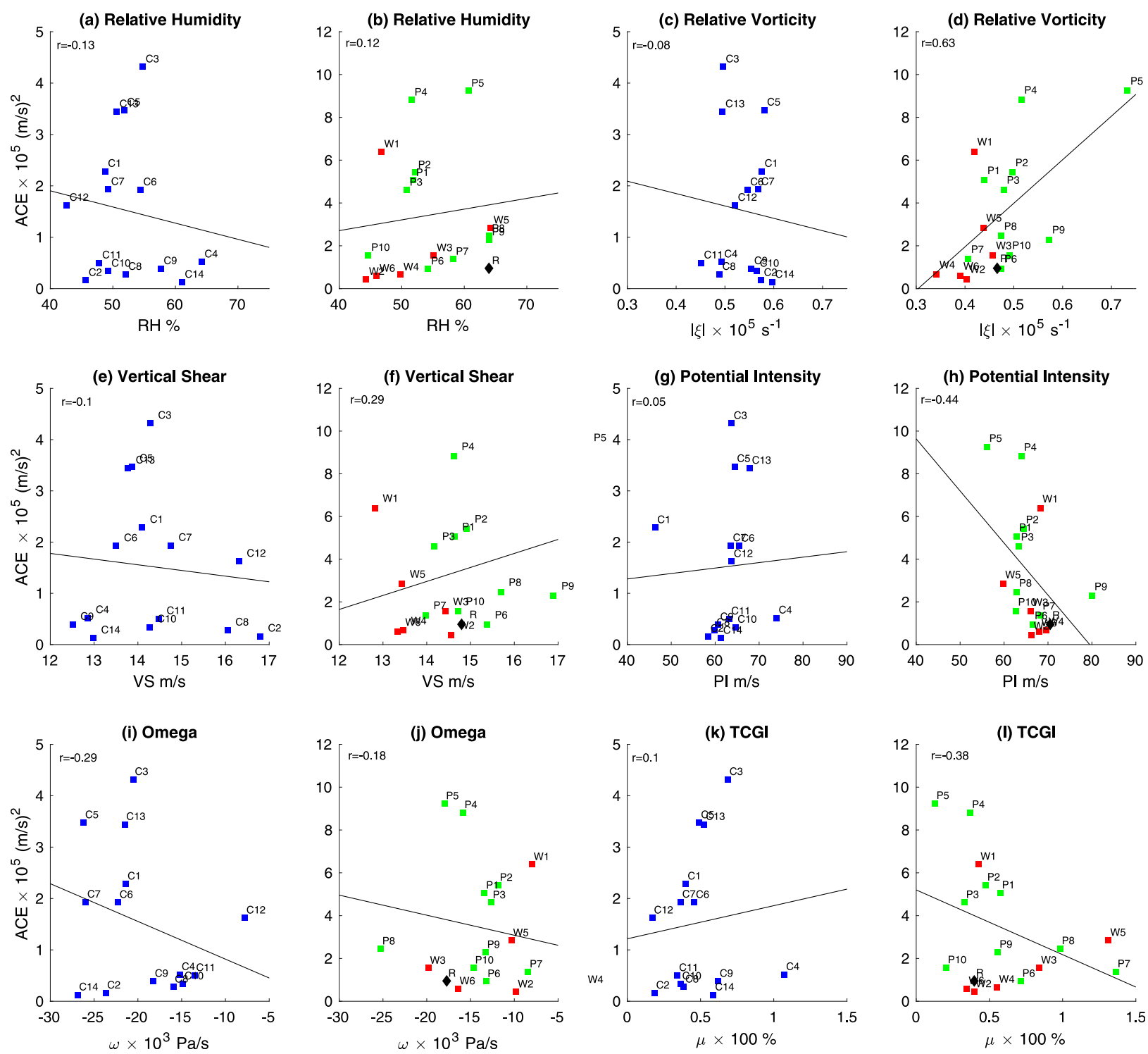

FIG. 14. Scatterplots of mean climatological ACE and environmental fields for the tropical Southern Hemisphere in JFM; $C$ (CMIP5) models are shown in blue, $W(\mathrm{HWG})$ models in red, $P$ (process-oriented) models in green, reanalysis $(R)$ in black. None of the correlations are statistically significant at the 95th significance level.

Furthermore, TCs do not respond passively to the large-scale environment; they can influence it (e.g., Sobel and Camargo 2005), although the exact magnitude and nature of this influence is not completely understood. This could be another reason why there is a lack of relationship between the simulated environment and TCs - the modeled environment might be partially a consequence of the modeled TC activity and this interaction might be model dependent.

One of the caveats of our analysis is that it can be sensitive to the tracking algorithm used by each modeling group. In the case of low-resolution models, this is not an issue, as the same tracking algorithm was used across models. The differences in tracking algorithm could potentially influence our results for high-resolution models, but as the sensitivity to tracking algorithm is not as critical for strong TCs and high-resolution models, we expect our results to be robust.

It is important to stress that our analysis was restricted to the relationship between the models' climatological environmental conditions and models' TC climatology. This does not preclude the existence of such relationship in nature. Furthermore, our results do not have implications for the ability of climate models to simulate TC variability, in particular the modulation of TC activity 
by modes of climate variability (e.g., El NiñoSouthern Oscillation or the Madden-Julian oscillation). It is well established that the variability of TC activity in models has the correct association with these climate modes, even if the model TC climatology is incorrect (Shaevitz et al. 2014; Wang et al. 2014; Han et al. 2016; Lee et al. 2018). Similarly, the response of the TC activity in models to climate change is not affected by our conclusions.

Acknowledgments. This work is a contribution to the process-oriented diagnostic effort of the NOAA (National Oceanic and Atmospheric Administration), MAPP (Modeling, Analysis, Predictions and Projections) Model Diagnostics Task Force, who also contributed with the simulations of two models in this study. This work was supported by NOAA's Climate Program Office's Modeling, Analysis, Predictions, and Projections program through Grant NA15OAR4310087. The authors thank all the members of U.S. CLIVAR Hurricane Working Group (HWG) for their contribution to this significant effort, in particular those who produced the model simulations used in this study. We would also like to thank Naomi Henderson for managing the HWG dataset. SJC, AHS, JDOS, and MK acknowledge support of NASA Grant 80NSSC17K0196. ES acknowledges support from the project PRIMAVERA, Grant Agreement 641727 of the Horizon 2020 research program. GAV is supported in part under NOAA Award NAOAR4320123. The statements, findings, conclusions, and recommendations are those of the authors and do not necessarily reflect the views of the National Oceanic and Atmospheric Administration, or the U.S. Department of Commerce.

Data availability statement: The CMIP5 and the Hurricane Working Group model datasets are available at https://esgf-node.llnl.gov/projects/cmip5/ and http://storms.ldeo.columbia.edu/. The ERA Interim reanalysis data can be obtained from https://www.ecmwf.int/ en/forecasts/datasets/reanalysis-datasets/era-interim. The best-track dataset from the National Hurricane Center and the Joint Typhoon Warning Center are available at https:// www.nhc.noaa.gov/data/ and https://www.metoc.navy.mil/ jtwc/jtwc.html?best-tracks. The data underlying the figures from this manuscript are available at the Columbia University Academic Commons repository at https:// academiccommons.columbia.edu/doi/10.7916/d8-t7y6-3f55.

\section{REFERENCES}

Bacmeister, J. T., K. A. Reed, C. Hannay, P. Lawrence, S. Bates, J. E. Truesdale, N. Rosenbloom, and M. Levy, 2018: Projected changes in tropical cyclone activity under future warming scenarios using a high-resolution climate model. Climatic Change, 146, 547-560, https://doi.org/10.1007/s10584-016-1750-x.
Bao, Q., and Coauthors, 2013: The Flexible Global Ocean-AtmosphereLand System model, spectral version 2: FGOALS-s2. Adv. Atmos. Sci., 30, 561-576, https://doi.org/10.1007/s00376-012-2113-9.

Bell, G. D., and Coauthors, 2000: Climate assessment for 1999. Bull. Amer. Meteor. Soc., 81 (6), S1-S50, https://doi.org/10.1175/ 1520-0477(2000)81[s1:CAF]2.0.CO;2.

Bengtsson, L., H. Böttger, and M. Kanamitsu, 1982: Simulation of hurricane-type vortices in a general circulation model. Tellus, 34, 440-457, https://doi.org/10.3402/tellusa.v34i5.10830.

_ warming over the next 50 years lead to higher frequency and greater intensity of hurricanes? Tellus, 48A, 57-73, https:// doi.org/10.3402/tellusa.v48i1.11632.

Bhatia, K., G. Vecchi, H. Murakami, S. Underwood, and J. Kossin, 2018: Projected response of tropical cyclone intensity and intensification in a global climate model. J. Climate, 31, 82818303, https://doi.org/10.1175/JCLI-D-17-0898.1.

Bister, M., and K. A. Emanuel, 2002: Low frequency variability of tropical cyclone potential intensity. 1. Interannual to interdecadal variability. J. Geophys. Res., 107, 4801, https://doi.org/ 10.1029/2001JD000776.

Bretherton, C. S., and S. Park, 2009: A new moist turbulence parameterization in the Community Atmosphere Model. J. Climate, 22, 3422-3448, https://doi.org/10.1175/2008JCLI2556.1.

_, M. E. Peters, and L. E. Back, 2004: Relationships between water vapor path and precipitation over the tropical oceans. J. Climate, 17, 1517-1528, https://doi.org/10.1175/15200442(2004)017<1517:RBWVPA > 2.0.CO;2.

Broccoli, A. J., and S. Manabe, 1990: Can existing climate models be used to study anthropogenic changes in tropical cyclone climate? Geophys. Res. Lett., 17, 1917-1920, https://doi.org/ 10.1029/GL017i011p01917.

Bruyère, C. L., G. J. Holland, and E. Towler, 2012: Investigating the use of a genesis potential index for tropical cyclones in the North Atlantic basin. J. Climate, 25, 8611-8626, https://doi.org/ 10.1175/JCLI-D-11-00619.1.

Camargo, S. J., 2013: Global and regional aspects of tropical cyclone activity in the CMIP5 models. J. Climate, 26, 9880-9902, https://doi.org/10.1175/JCLI-D-12-00549.1.

— of tropical storms in atmospheric general circulation models. Wea. Forecasting, 17, 1152-1162, https://doi.org/10.1175/15200434(2002)017<1152:ITDATO>2.0.CO;2.

_ , and A. G. Barnston, 2009: Experimental seasonal dynamical forecasts of tropical cyclone activity at IRI. Wea. Forecasting, 24, 472-491, https://doi.org/10.1175/2008WAF2007099.1.

_ , and A. A. Wing, 2016: Tropical cyclones in climate models. Wiley Interdiscip. Rev. Climate Change, 7, 211-237, https:// doi.org/10.1002/wcc.373.

_ , and L. M. Polvani, 2019: Little evidence of reduced global tropical cyclone activity following recent volcanic eruptions. npj Climate Atmos. Sci., 2, 14, https://doi.org/10.1038/S41612019-0070-Z.

— A. G. Barnston, and S. E. Zebiak, 2005: A statistical assessment of tropical cyclone activity in atmospheric general circulation models. Tellus, 57A, 589-604, https://doi.org/10.3402/ tellusa.v57i4.14705.

_ K. A. Emanuel, and A. H. Sobel, 2007a: Use of a genesis potential index to diagnose ENSO effects on tropical cyclone genesis. J. Climate, 20, 4819-4834, https://doi.org/10.1175/JCLI4282.1. , A. H. Sobel, A. G. Barnston, and K. A. Emanuel, 2007b: Tropical cyclone genesis potential index in climate models. Tellus, 59A, 428-443, https://doi.org/10.1111/j.1600-0870.2007.00238.x. 
— M. K. Tippett, A. H. Sobel, G. A. Vecchi, and M. Zhao, 2014: Testing the performance of tropical cyclone genesis indices in future climates using the HIRAM model. J. Climate, 27, 91719196, https://doi.org/10.1175/JCLI-D-13-00505.1.

— A. H. Sobel, A. D. Del Genio, J. A. Jonas, M. Kelley, Y. Lu, D. A. Shaevitz, and N. Henderson, 2016: Tropical cyclones in the GISS ModelE2. Tellus, 68A, 31494, https://doi.org/ 10.3402/tellusa.v68.31494.

Camp, J., and Coauthors, 2018: Skilful multi-week tropical cyclone prediction in ACCESS-S1 and the role of the MJO. Quart. J. Roy. Meteor. Soc., 144, 1337-1351, https://doi.org/10.1002/ qj.3260.

—_ and Coauthors, 2019: The western Pacific subtropical high and tropical cyclone landfall: Seasonal forecasts using the Met Office GloSea5 system. Quart. J. Roy. Meteor. Soc., 145, 105116, https://doi.org/10.1002/qj.3407.

Cesana, G., A. D. Del Genio, A. S. Ackerman, M. Kelley, G. Elsaesser, A. M. Fridlind, Y. Cheng, and M.-S. Yao, 2019: Evaluating models' response of tropical low clouds to SST forcings using CALIPSO observations. Atmos. Chem. Phys., 19, 2813-2832, https://doi.org/10.5194/acp-19-2813-2019.

Chand, S. S., K. J. Tory, H. Ye, and K. J. E. Walsh, 2017: Projected increase in El Niño-driven tropical cyclone frequency in the Pacific. Nat. Climate Change, 7, 123-127, https://doi.org/ 10.1038/nclimate3181.

Cherchi, A., and Coauthors, 2019: Global mean climate and main patterns of variability in the CMCC-CM2 coupled model. J. Adv. Model. Earth Syst., 11, 185-209, https://doi.org/10.1029/ 2018MS001369.

Chu, J.-H., C. R. Sampson, A. S. Levine, and E. Fukada, 2002: The Joint Typhoon Warning Center tropical cyclone best-tracks, 1945-2000. Naval Research Laboratory Tech. Rep. NRL/MR/ 7540-02-16, $112 \mathrm{pp}$.

Daloz, A. S., and Coauthors, 2015: Cluster analysis of downscaled and explicitly simulated North Atlantic tropical cyclone tracks. J. Climate, 28, 1333-1361, https://doi.org/10.1175/ JCLI-D-13-00646.1.

Davis, C. A., 2018: Resolving tropical cyclone intensity in models. Geophys. Res. Lett., 45, 2082-2087, https://doi.org/10.1002/ 2017GL076966.

Dee, D. P., and Coauthors, 2011: The ERA-Interim reanalysis: Configuration and performance of the data assimilation system. Quart. J. Roy. Meteor. Soc., 137, 553-597, https://doi.org/ 10.1002/qj.828.

Del Genio, A. D., J. Wu, A. G. Wolf, Y. Chen, M.-S. Yao, and D. Kim, 2015: Constraints on cumulus parameterization from simulations of observed MJO events. J. Climate, 28, 64196442, https://doi.org/10.1175/JCLI-D-14-00832.1.

Delworth, T. L., and Coauthors, 2012: Simulated climate and climate change in the GFDL CM2.5 high-resolution coupled climate model. J. Climate, 25, 2755-2781, https://doi.org/10.1175/ JCLI-D-11-00316.1.

DeMaria, M., and J. Kaplan, 1994: A Statistical Hurricane Intensity Prediction Scheme (SHIPS) for the Atlantic basin. Wea. Forecasting, 9, 209-220, https://doi.org/10.1175/15200434(1994)009<0209:ASHIPS > 2.0.CO;2.

_ J. A. Knaff, and B. H. Conell, 2001: A tropical cyclone genesis parameter for the tropical Atlantic. Wea. Forecasting, 16, 219-233, https://doi.org/10.1175/1520-0434(2001)016<0219: ATCGPF $>2.0 . \mathrm{CO} ; 2$.

Donner, L. J., and Coauthors, 2011: The dynamical core, physical parameterizations, and basic simulation characteristics of the atmospheric component of the GFDL global coupled model CM3. J. Climate, 24, 3484-3519, https://doi.org/10.1175/ 2011JCLI3955.1.

Duvel, J.-P., S. J. Camargo, and A. H. Sobel, 2017: Role of convection scheme in modeling initiation and intensification of tropical depressions over the North Atlantic. Mon. Wea. Rev., 145, 1495-1509, https://doi.org/10.1175/MWRD-16-0201.1.

Emanuel, K. A., 1988: The maximum intensity of hurricanes. J. Atmos. Sci., 45, 1143-1155, https://doi.org/10.1175/15200469(1988)045<1143:TMIOH > 2.0.CO;2.

_- 2000: A statistical analysis of tropical cyclone intensity. Mon. Wea. Rev., 128, 1139-1152, https://doi.org/10.1175/ 1520-0493(2000)128<1139:ASAOTC > 2.0.CO;2.

- 2010: Tropical cyclone activity downscaled from NOAACIRES reanalysis, 1908-1958. J. Adv. Model. Earth Syst., 2 (1), https://doi.org/10.3894/JAMES.2010.2.1.

_ 2018: 100 years of progress in tropical cyclone research. A Century of Progress in Atmospheric and Related Sciences: Celebrating the American Meteorological Society Centennial, Meteor. Monogr., 15.1-15.68, https://doi.org/10.1175/AMSMONOGRAPHS-D$18-0016.1$.

- and D. S. Nolan, 2004: Tropical cyclone activity and global climate. Bull. Amer. Meteor. Soc., 85, 666-667.

Gent, P. R., and Coauthors, 2011: The Community Climate System Model version 4. J. Climate, 24, 4973-4991, https://doi.org/ 10.1175/2011JCLI4083.1.

Gettelman, A., and H. Morrison, 2015: Advanced two-moment bulk microphysics for global models. Part I: Off-line tests and comparison with other schemes. J. Climate, 28, 1268-1287, https://doi.org/10.1175/JCLI-D-14-00102.1.

Gray, W. M., 1968: Global view of the origin of tropical disturbances and storms. Mon. Wea. Rev., 96, 669700, https://doi.org/10.1175/1520-0493(1968)096<0669: GVOTOO $>2.0 . \mathrm{CO} ; 2$

_ 1979: Hurricanes: Their formation, structure and likely role in the tropical circulation. Meteorology over the Tropical Oceans, D. B. Shaw, Ed., Royal Meteorological Society, 155-218.

Gregory, P. A., J. Camp, K. Bigelow, and A. Brown, 2019: Subseasonal predictability of the 2017-2018 Southern Hemisphere tropical cyclone season. Atmos. Sci. Lett., 20, e886, https:// doi.org/10.1002/asl.886.

Haarsma, R. J., J. F. B. Mitchell, and C. A. Senior, 1993: Tropical disturbances in a GCM. Climate Dyn., 8, 247-257, https:// doi.org/10.1007/BF00198619.

Han, R., and Coauthors, 2016: An assessment of multi-model simulations on the variability of western North Pacific tropical cyclones and its association with ENSO. J. Climate, 29, 64016423, https://doi.org/10.1175/JCLI-D-15-0720.1.

Held, I. M., and M. Zhao, 2011: The response of tropical cyclone statistics to an increase in $\mathrm{CO}_{2}$ with fixed sea surface temperatures. J. Climate, 24, 5353-5364, https://doi.org/10.1175/ JCLI-D-11-00050.1.

Horn, M., and Coauthors, 2014: Tracking scheme dependence of simulate tropical cyclone response to idealized climate simulations. J. Climate, 27, 9197-9213, https://doi.org/10.1175/ JCLI-D-14-00200.1.

Jones, C. D., and Coauthors, 2011: The HadGEM2-ES implementation of CMIP5 centennial simulations. Geosci. Model Dev., 4, 543-570, https://doi.org/10.5194/gmd-4-543-2011.

Kim, D., A. H. Sobel, A. D. Del Genio, Y. Chen, S. J. Camargo, M.-S. Yao, M. Kelley, and L. Nazarenko, 2012: The tropical subseasonal variability simulated in the NASA GISS general 
circulation model. J. Climate, 25, 4641-4659, https://doi.org/ 10.1175/JCLI-D-11-00447.1.

— , and Coauthors, 2018: Process-oriented diagnosis of tropical cyclones in high-resolution GCMs. J. Climate, 31, 1685-1702, https://doi.org/10.1175/JCLI-D-17-0269.1.

Knutson, T. R., and Coauthors, 2013: Dynamical downscaling projections of twenty-first-century Atlantic hurricane activity: CMIP3 and CMIP5 model-based scenarios. J. Climate, 26, 6591-6617, https://doi.org/10.1175/JCLI-D-12-00539.1.

Kossin, J. P., and S. J. Camargo, 2009: Hurricane track variability and secular potential intensity trends. Climatic Change, 97, 329-337, https://doi.org/10.1007/s10584-009-9748-2.

_ K. A. Emanuel, and S. J. Camargo, 2016: Past and projected changes in western North Pacific tropical cyclone exposure. J. Climate, 29, 5725-5739, https://doi.org/10.1175/JCLI-D-160076.1.

Landsea, C. W., and J. L. Franklin, 2013: Atlantic hurricane database uncertainty and presentation of a new database format. Mon. Wea. Rev., 141, 3576-3592, https://doi.org/10.1175/ MWR-D-12-00254.1.

Lee, C.-Y., S. J. Camargo, F. Vitart, A. H. Sobel, and M. K. Tippett, 2018: Subseasonal tropical cyclone genesis prediction and MJO in the S2S dataset. Wea. Forecasting, 33, 967-988, https:// doi.org/10.1175/WAF-D-17-0165.1.

Li, H., and R. L. Sriver, 2018: Tropical cyclone activity in the highresolution Community Earth System Model and the impact of ocean coupling. J. Adv. Model. Earth Syst., 10, 165-186, https://doi.org/10.1002/2017MS001199.

Maloney, E. D., and Coauthors, 2019: Process-oriented evaluation of climate and weather forecasting models. Bull. Amer. Meteor. Soc., 100, 1665-1686, https://doi.org/10.1175/BAMS-D-18-0042.1.

Manabe, S., J. L. Holloway, and H. M. Stone, 1970: Tropical circulation in a time-integration of a global model of the atmosphere. J. Atmos. Sci., 27, 580-613, https://doi.org/10.1175/ 1520-0469(1970)027<0580:TCIATI >2.0.CO;2.

Manganello, J. V., and Coauthors, 2012: Tropical cyclone climatology in a 10-km global atmospheric GCM: Toward weatherresolving climate modeling. J. Climate, 25, 3867-3893, https:// doi.org/10.1175/JCLI-D-11-00346.1.

—_, and Coauthors, 2014: Future changes in the western North Pacific tropical cyclone activity projected by a multidecadal simulation with a 16-km global atmospheric GCM. J. Climate, 27, 7622-7646, https://doi.org/10.1175/JCLI-D-13-00678.1.

— , and Coauthors, 2016: Seasonal forecasts of tropical cyclone activity in a high-atmospheric-resolution coupled prediction system. J. Climate, 29, 1179-1200, https://doi.org/10.1175/ JCLI-D-15-0531.1.

McBride, J. L., and R. Zehr, 1981: Observational analysis of tropical cyclone formation. Part II: Comparison of nondeveloping versus non-developing systems. J. Atmos. Sci., 38, 1132-1151, https://doi.org/10.1175/1520-0469(1981)038<1132: OAOTCF $>2.0 . \mathrm{CO} ; 2$.

Menkes, C. E., M. Lengaigne, P. Marchesiello, N. C. Jourdain, E. M. Vincent, J. Lefèvre, F. Chauvin, and J.-F. Royer, 2012: Comparison of tropical cyclonegenesis indices on seasonal to interannual timescales. Climate Dyn., 38, 301-321, https:// doi.org/10.1007/s00382-011-1126-x.

Molod, A., L. Takacs, M. Suarez, and J. Bacmeister, 2015: Development of the GEOS-5 atmospheric general circulation model: Evolution from MERRA to MERRA2. Geosci. Model Dev., 8, 1339-1356, https://doi.org/10.5194/gmd-8-1339-2015.

Moon, Y., and Coauthors, 2020: Wind and thermodynamic structures of tropical cyclones in global climate models and their sensitivity to horizontal resolution. J. Climate, 33, 1575-1595, https://doi.org/10.1175/JCLI-D-19-0172.1.

Murakami, H., and M. Sugi, 2010: Effect of model resolution on tropical cyclone climate projections. SOLA, 6, 73-76, https:// doi.org/10.2151/SOLA.2010-019.

, and B. Wang, 2010: Future change of North Atlantic tropical cyclone tracks: Projection by a 20-km-mesh global atmospheric model. J. Climate, 23, 2699-2721, https://doi.org/ 10.1175/2010JCLI3338.1.

_ R. Mizuta, and E. Shindo, 2012a: Future changes in tropical cyclone activity projected by multi-physics and multi-SST ensemble experiments using the 60-km-mesh MRI-AGCM. Climate Dyn., 39, 2569-2584, https://doi.org/10.1007/s00382011-1223-x.

, and Coauthors, 2012b: Future changes in tropical cyclone activity projected by the new high-resolution MRI-AGCM. J. Climate, 25, 3237-3260, https://doi.org/10.1175/JCLI-D-1100415.1.

— , P.-C. Hsu, O. Arakawa, and T. Li, 2014: Influence of model biases on projected future changes in tropical cyclone frequency of occurrence. J. Climate, 27, 2159-2181, https:// doi.org/10.1175/JCLI-D-13-00436.1.

- and Coauthors, 2015: Simulation and prediction of category 4 and 5 hurricanes in the high-resolution GFDL HiFLOR coupled climate model. J. Climate, 28, 9058-9079, https://doi.org/ 10.1175/JCLI-D-15-0216.1.

Nakamura, J., and Coauthors, 2017: Western North Pacific tropical cyclone model tracks in present and future climates. J. Geophys. Res. Atmos., 122, 9721-9744, https:// doi.org/10.1002/2017JD027007.

Neale, R. B., and Coauthors, 2012: Description of the NCAR Community Atmosphere Model (CAM 5.0). NCAR Tech. Note NCAR/TN-486+STR, 274 pp., www.cesm.ucar.edu/ models/cesm1.0/cam/docs/description/cam5_desc.pdf.

Nolan, D. S., E. D. Rappin, and K. A. Emanuel, 2007: Tropical cyclogenesis sensitivity to environmental parameters in radiativeconvective equilibrium. Quart. J. Roy. Meteor. Soc., 133, 20852107, https://doi.org/10.1002/qj.170.

Palmén, E., 1948: On the formation and structure of tropical hurricanes. Geophysica, 3, 26-38.

Pausata, F. S. R., and S. J. Camargo, 2019: Tropical cyclone activity affected by volcanically induced ITCZ shifts. Proc. Natl. Acad. Sci. USA, 116, 7732-7737, https://doi.org/10.1073/ pnas. 1900777116.

Prabhat, O., Rubel, S. Byna, K. S. Wu, M. Wehner, and W. Bethel, 2012: TECA: A parallel toolkit for extreme climate analysis. Procedia Comput. Sci., 9, 866-876, https://doi.org/10.1016/ j.procs.2012.04.093.

Putman, W., and S.-J. Lin, 2007: Finite-volume transport on various cubed-sphere grids. J. Comput. Phys., 227, 55-78, https:// doi.org/10.1016/j.jcp.2007.07.022.

Ramsay, H. A., S. S. Chand, and S. J. Camargo, 2018: A statistical assessment of Southern Hemisphere tropical cyclone tracks in climate models. J. Climate, 31, 10 081-10 104, https://doi.org/ 10.1175/JCLI-D-18-0377.1.

Rappin, E. D., D. S. Nolan, and K. A. Emanuel, 2010: Thermodynamic control of tropical cyclogenesis in environments of radiativeconvective equilibrium with shear. Quart. J. Roy. Meteor. Soc., 136, 1954-1971, https://doi.org/10.1002/qj.706.

Reed, K. A., and C. Jablonowski, 2011: Impact of physical parametrization on idealized tropical cyclones in the Community Atmosphere Model. Geophys. Res. Lett., 38, L04805, https:// doi.org/10.1029/2010GL046297. 
—, J. T. Bacmeister, N. A. Rosenblum, M. F. Wehner, S. C. Bates, P. H. Lauritzen, J. E. Truesdale, and C. Hannay, 2015: Impact of the dynamical core on the direct simulation of tropical cyclones in a high-resolution global model. Geophys. Res. Lett., 42, 3603-3608, https://doi.org/10.1002/ 2015 GL063974.

Rienecker, M. M., and Coauthors, 2008: The GEOS-5 data assimilation system-Documentation of versions 5.0.1, 5.1.0, and 5.2.0. Tech. Rep. series on Global Modeling and Data Assimilation, 27, NASA/TM-2008-104606, 101 pp.

Roberts, M. J., and Coauthors, 2015: Tropical cyclones in the UPSCALE ensemble of high-resolution global climate models. J. Climate, 28, 574-596, https://doi.org/10.1175/ JCLI-D-14-00131.1.

— for climate simulation: Process understanding and the enabling of stakeholder decisions at the regional scale. Bull. Amer. Meteor. Soc., 99, 2341-2359, https://doi.org/10.1175/ BAMS-D-15-00320.1.

Roeckner, E., and Coauthors, 2003: The atmospheric general circulation model ECHAM5. Part I: Model description. Tech. Rep. 349, Max-Planck Institute for Meteorology, Hamburg, Germany, $127 \mathrm{pp}$.

Rotstayn, L. D., S. J. Jeffrey, M. A. Collier, S. M. Dravitzki, A. C. Hirst, J. I. Syktus, and K. K. Wong, 2012: Aerosol- and greenhouse gas-induced changes in summer rainfall and circulation in the Australasian region: A study using singleforcing climate simulations. Atmos. Chem. Phys., 12, 63776404, https://doi.org/10.5194/acp-12-6377-2012.

Saha, S., and Coauthors, 2014: The NCEP Climate Forecast System version 2. J. Climate, 27, 2185-2208, https://doi.org/10.1175/ JCLI-D-12-00823.1.

Schmidt, G. A., and Coauthors, 2014: Configuration and assessment of GISS ModelE2 contributions to the CMIP5 archive. J. Adv. Model. Earth Syst., 6, 141-184, https://doi.org/10.1002/ 2013MS000265.

Scoccimarro, E., and Coauthors, 2011: Effects of tropical cyclones on ocean heat transport in a high-resolution coupled general circulation model. J. Climate, 24, 4368-4384, https://doi.org/ 10.1175/2011JCLI4104.1.

_ S. Gualdi, G. Villarini, G. A. Vecchi, M. Zhao, K. Walsh, and A. Navarra, 2014: Increased precipitation events associated with landfalling tropical cyclones in response to a warmer climate and increased $\mathrm{CO}_{2}$. J. Climate, 27, 4642-4654, https:// doi.org/10.1175/JCLI-D-14-00065.1.

_ , P. G. Fogli, K. A. Reed, S. Gualdi, S. Masina, and A. Navarra, 2017: Tropical cyclone interaction with the ocean: The role of high-frequency (subdaily) coupled processes. J. Climate, 30, 145-162, https://doi.org/10.1175/JCLI-D-16-0292.1.

Shaevitz, D. A., and Coauthors, 2014: Characteristics of tropical cyclones in high-resolution models of the present climate. J. Adv. Model. Earth Syst., 6, 1154-1172, https://doi.org/ 10.1002/2014MS000372.

Sobel, A. H., and S. J. Camargo, 2005: Influence of western North Pacific tropical cyclones on their environment. J. Atmos. Sci., 62, 3396-3407, https://doi.org/10.1175/JAS3539.1.

Strachan, J., P. L. Vidale, K. Hodges, M. Roberts, and M.-E. Demory, 2013: Investigating global tropical cyclone activity with a hierarchy of AGCMs: The role of model resolution. J. Climate, 26, 133-152, https://doi.org/10.1175/JCLI-D-12-00012.1.

Tang, B., and K. Emanuel, 2010: Midlevel ventilation's constraint on tropical cyclone intensity. J. Atmos. Sci., 67, 1817-1830, https://doi.org/10.1175/2010JAS3318.1.
— and - 2012a: Sensitivity of tropical cyclone intensity to ventilation in an axisymmetric model. J. Atmos. Sci., 69, 23942413, https://doi.org/10.1175/JAS-D-11-0232.1.

$\longrightarrow$, and $-2012 \mathrm{~b}$ : A ventilation index for tropical cyclones. Bull. Amer. Meteor. Soc., 93, 1901-1912, https://doi.org/ 10.1175/BAMS-D-11-00165.1.

— , and S. J. Camargo, 2014: Environmental control of tropical cyclones in CMIP5: A ventilation perspective. J. Adv. Model. Earth Syst., 6, 115-128, https://doi.org/10.1002/2013MS000294.

Taylor, K. E., R. J. Stouffer, and G. A. Meehl, 2012: An overview of CMIP5 and the experiment design. Bull. Amer. Meteor. Soc., 93, 485-498, https://doi.org/10.1175/BAMS-D-11-00094.1.

Tippett, M. K., S. J. Camargo, and A. H. Sobel, 2011: A Poisson regression index for tropical cyclone genesis and the role of large-scale vorticity in genesis. J. Climate, 24, 2335-2357, https://doi.org/10.1175/2010JCLI3811.1.

Tory, K. J., S. S. Chand, J. L. McBride, H. Ye, and R. A. Dare, 2013: Projected changes in late-twenty-first-century tropical cyclone frequency in 13 coupled climate models from phase 5 of the Coupled Model Intercomparison Project. J. Climate, 26, 99469959, https://doi.org/10.1175/JCLI-D-13-00010.1.

Ullrich, P. A., and C. M. Zarzycki, 2017: TempestExtremes: A framework for scale-insensitive pointwise feature tracking on unstructured grids. Geosci. Model Dev., 10, 1069-1090, https:// doi.org/10.5194/gmd-10-1069-2017.

Vecchi, G. A., and Coauthors, 2014: On the seasonal forecasting of regional tropical cyclone activity. J. Climate, 27, 7994-8016, https://doi.org/10.1175/JCLI-D-14-00158.1.

_ - and Coauthors, 2019: The response of tropical-cyclone permitting coupled global climate models to $\mathrm{CO}_{2}$ doubling: Largescale surface climate and tropical cyclone activity. Climate Dyn., 53, 5999-6033, https://doi.org/10.1007/s00382-019-04913-y.

Villarini, G., D. A. Lavers, E. Scoccimarro, M. Zhao, M. F. Wehner, G. A. Vecchi, T. R. Knutson, and K. A. Reed, 2014: Sensitivity of tropical cyclone rainfall to idealized global scale forcings. J. Climate, 27, 4622-4641, https://doi.org/10.1175/JCLI-D-13-00780.1.

Vitart, F., 2009: Impact of the Madden Julian Oscillation on tropical storms and risk of landfall in the ECMWF forecast system. Geophys. Res. Lett., 36, L15802, https://doi.org/ 10.1029/2009GL039089.

_ J. L. Anderson, J. Sirutis, and R. E. Tuleya, 2001: Sensitivity of tropical storms simulated by a general circulation model to changes in cumulus parametrization. Quart. J. Roy. Meteor. Soc., 127, 25-51, https://doi.org/10.1002/qj.49712757103.

_ D. Anderson, and T. Stockdale, 2003: Seasonal forecasting of tropical cyclone landfall over Mozambique. J. Climate, 16, 3932-3945, https://doi.org/10.1175/1520-0442(2003)016<3932: SFOTCL $>2.0 . \mathrm{CO} ; 2$.

Voldoire, A., and Coauthors, 2013: The CNRM-CM5.1 global climate model: Description and basic evaluation. Climate Dyn., 40, 2091-2121, https://doi.org/10.1007/s00382-011-1259-y.

Volodin, E. M., N. A. Dianskii, and A. V. Gusev, 2010: Simulating present-day climate with INMCM4.0 coupled model of the atmospheric and oceanic general circulations. Izv. Atmos. Ocean Phys., 46, 414-431, https://doi.org/10.1134/S000143381004002X.

von Salzen, K., and Coauthors, 2013: The Canadian fourth generation atmospheric global climate model (CanAM4). Part I: Representation of physical processes. Atmos. -Ocean, 51, 104125, https://doi.org/10.1080/07055900.2012.755610.

Walsh, K., S. Lavender, E. Scoccimarro, and H. Murakami, 2013: Resolution dependence of tropical cyclone formation in CMIP3 and finer resolution models. Climate Dyn., 40, 585599, https://doi.org/10.1007/s00382-012-1298-z. 
—, M. Fiorino, C. W. Landsea, and K. L. McInnes, 2007: Objectively determined resolution-dependent threshold criteria for the detection of tropical cyclones in climate models and reanalyses. J. Climate, 20, 2307-2314, https://doi.org/ 10.1175/JCLI4074.1.

_ , and Coauthors, 2015: Hurricanes and climate: The U.S. CLIVAR working group on hurricanes. Bull. Amer. Meteor. Soc., 96, 997-1017, https://doi.org/10.1175/BAMS-D-1300242.1.

Wang, H., and Coauthors, 2014: How well do global climate models simulate the variability of Atlantic tropical cyclones associated with ENSO? J. Climate, 27, 5673-5692, https://doi.org/ 10.1175/JCLI-D-13-00625.1.

Watanabe, M., and Coauthors, 2010: Improved climate simulation by MIROC5: Mean states, variability, and climate sensitivity. J. Climate, 23, 6312-6335, https://doi.org/10.1175/2010JCLI3679.1.

Watanabe, S., and Coauthors, 2011: MIROC-ESM 2010: Model description and basic results of CMIP5-20c3m experiments. Geosci. Model Dev., 4, 845-872, https://doi.org/10.5194/gmd-4845-2011.

Wehner, M., Prabhat, K.A. Reed, D. Stone, W.D. Collins, and J. Bacmeister, 2015: Resolution dependence of future tropical cyclone projections of CAM5.1 in the U.S. CLIVAR hurricane working group idealized configurations. J. Climate, $\mathbf{2 8}$, 3905-3925, https://doi.org/10.1175/JCLI-D-14-00311.1.

_ , and Coauthors, 2014: The effect of horizontal resolution on simulation quality in the Community Atmospheric Model CAM5.1. J. Adv. Model. Earth Syst., 6, 980-997, https://doi.org/ 10.1002/2013MS000276.

Wing, A. A., A. H. Sobel, and S. J. Camargo, 2007: The relationship between the potential and actual intensities of tropical cyclones. Geophys. Res. Lett., 34, L08810, https://doi.org/ 10.1029/2006GL028581.

_ - and Coauthors, 2019: Moist static energy budget analysis of tropical cyclone intensification in high-resolution climate models. J. Climate, 32, 6071-6095, https://doi.org/10.1175/ JCLI-D-18-0599.1.

Yukimoto, S., and Coauthors, 2012: A new global climate model of the Meteorological Research Institute: MRI-CGCM3-Model description and basic performance. J. Meteor. Soc. Japan, 90A, 23-64, https://doi.org/10.2151/jmsj.2012-A02.

Zanchettin, D., A. Rubino, D. Matei, O. Bothe, and J. H Jungclaus, 2013: Multidecadal-to-centennial SST variability in the MPI-ESM simulation ensemble for the last millennium. Climate Dyn., 40, 1301-1318, https://doi.org/10.1007/s00382012-1361-9.

Zarzycki, C. M., 2016: Tropical cyclone intensity errors associated with lack of two-way ocean coupling in high-resolution global simulations. J. Climate, 29, 8589-8610, https://doi.org/10.1175/ JCLI-D-16-0273.1.
, and P. A. Ullrich, 2017: Assessing sensitivities in algorithmic detection of tropical cyclones in climate data. Geophys. Res. Lett., 44,1141-1149, https://doi.org/10.1002/ 2016 GL071606.

— C. Jablonowski, and M. A. Taylor, 2014: Using variableresolution meshes to model tropical cyclones in the Community Atmosphere Model. Mon. Wea. Rev., 142, 1221-1239, https:// doi.org/10.1175/MWR-D-13-00179.1.

—, D. R. Thatcher, and C. Jablonowski, 2017: Objective tropical cyclone extratropical transition detection in high-resolution reanalysis and climate model data. J. Adv. Model. Earth Syst., 9, 130-148, https://doi.org/10.1002/2016MS000775.

Zhang, G., H. Murakami, R. Gudgel, and X. Yang, 2019: Dynamical seasonal prediction of tropical cyclone activity: Robust assessment of prediction skill and predictability. Geophys. Res. Lett., 46, 5506-5515, https://doi.org/10.1029/ 2019GL082529.

Zhang, W., G. Villarini, G. A. Vecchi, and H. Murakami, 2019: Rainfall from tropical cyclones: High-resolution simulations and seasonal forecasts. Climate Dyn., 52, 5269-5289, https:// doi.org/10.1007/s00382-018-4446-2.

Zhang, Z. S., and Coauthors, 2012: Pre-industrial and mid-Pliocene simulations with NorESM-L. Geosci. Model Dev., 5, 523-533, https://doi.org/10.5194/gmd-5-523-2012.

Zhao, C., H.-L. Ren, R. Eade, Y. Wu, J. Wu, and C. MacLachlan, 2019: MJO modulation and its ability to predict boreal summer tropical cyclone genesis over the northwest Pacific in Met Office Hadley Centre and Beijing Climate Center seasonal prediction systems. Quart. J. Roy. Meteor. Soc., 145, 10891101, https://doi.org/10.1002/qj.3478.

Zhao, M., and I. M. Held, 2012: TC-permitting GCM simulations of hurricane frequency response to sea surface temperature anomalies projected for the late-twenty-first century. J. Climate, 25, 2995-3009, https://doi.org/10.1175/JCLI-D-11-00313.1.

, - - S.-J. Lin, and G. A. Vecchi, 2009: Simulations of global hurricane climatology, interannual variability and response to global warming using a 50-km resolution GCM. J. Climate, 22, 6653-6678, https://doi.org/10.1175/2009JCLI3049.1.

- — — and - 2012: Some counterintuitive dependencies of tropical cyclone frequency on parameters in a GCM. J. Atmos. Sci., 69, 2272-2283, https://doi.org/10.1175/JASD-11-0238.1.

, and Coauthors, 2018a: The GFDL global atmosphere and land model AM4.0/LM4.0: 1. Simulation characteristics with prescribed SSTs. J. Adv. Model. Earth Syst., 10, 691-734, https://doi.org/10.1002/2017MS001208.

and Coauthors, 2018b: The GFDL global atmosphere and land model AM4.0/LM4.0: 2. Model description, sensitivity studies, and tuning strategies. J. Adv. Model. Earth Syst., 10, 735-769, https://doi.org/10.1002/2017MS001209. 